\title{
1 On the shape of things: A geometric morphometrics approach to investigate
}

2 Aurignacian group membership

4 DOYON, Luc ${ }^{1,2 *}$

$6{ }^{1}$ Institute of Cultural Heritage, Shandong University, 27 Shanda Nanlu, Jinan, 250100,

7 China

$8 \quad{ }^{2}$ Centre National de la Recherche Scientifique, UMR 5199 - PACEA, Université de

9 Bordeaux, Bât. B18, Allée Geoffroy Saint Hilaire, CS 50023, 33615 Pessac Cedex,

10 France

$12{ }^{*}$ Corresponding author: luc.doyon@umontreal.ca

\section{Abstract}

15 The manufacture of composite projectile technology requires the production and

16 assemblage of tightly fitted parts designed to fulfill a number of distinct functions. Each

17 part combines a number of techno-functional units, and various processes may be

18 responsible for the shape variability of these units. In order to investigate the relative

19 contribution of each process to the overall variability of a projectile implement, one must

20 identify the point of demarcation between its techno-functional units. In the present

21 paper, the concept of shape modularity is introduced to precisely identify this locus. The

22 application of geometric morphometrics and shape modularity to the study of two

23 Aurignacian osseous projectile point types, i.e., split- and massive-based points, reveals

24 interesting patterns. On both types, the maximum width delimits the distal and proximal

25 techno-functional units of these objects. When focusing on the morphometric variability

26 and the geographic distribution of the implements' proximal unit, the eight shapes

27 identified for split-based points are found over vast regions of Europe. On the other hand,

28 the two proximal shapes defined for massive-based points show a pattern of local, or

29 regional, aggregation. These proximal shapes were likely considered fit for hafting and

30 hunting by the prehistoric populations who reproduced them, and they are interpreted as a

31 proxy for the socially shared rules of production that guided the manufacture of these tool 
32 types. They could therefore be used in future studies that aim to identify group

33 membership amongst the Aurignacian metapopulation and the extent of their interactions.

35 Keywords: Bone technology; Projectile points; Early Upper Palaeolithic; Europe; Shape 36 modularity

\section{Highlights}

- A geometric morphometric method is described to analyze tools with simple outlines

- Shape modularity test is used to identify techno-functional components of an object

- For split-based points, eight distinct proximal shapes are found over vast regions

- The two proximal shapes identified for massive-based points are locally aggregated

- The proximal shapes represent a proxy for the socially shared rules of production

\section{Introduction}

The Aurignacian is a key technocomplex of the European Early Upper Palaeolithic. Its associated archaeological record is characterized by the co-occurrence of cultural items usually attributed to anatomically modern human behavior (Henshilwood and Marean, 2003; McBrearty and Brooks, 2000), such as the widespread adoption of blade and bladelet technology, the manufacture of bone technology, and the production of art and of a rich symbolic material culture. One aspect of Aurignacian material culture is of particular interest as it plays a central role in the definition of the different phases of the technocomplex. It consists of the projectile points made of antler, bone, and ivory. These elongated armatures with a simple outline are divided into two types, i.e., split- and massive-based points. The presence or absence of a split on the proximal portion, visible

59 from the lateral view of the object, serves as a criterion for their typological

60 categorization (Hahn, 1988a, 1988b). Split-based points are usually associated with Early

61 Aurignacian archaeological contexts ( $\sim 40-36 \mathrm{ka} \mathrm{BP})$ and massive-based points with the

62 Middle and Later phases of the Aurignacian ( $\sim 37-32 \mathrm{ka} \mathrm{BP})$. 
Previous attempts have failed to identify patterned variation amongst split- and massive-based points (Albrecht et al., 1972; Clément and Leroy-Prost, 1977; Knecht, 1991; Turk, 2002, 2003, 2005). The methodology and the analytical tools selected to study the armatures' shape are two factors at the root of this inconclusive outcome. From

67 a methodological standpoint, the works by Turk $(2002,2003,2005)$ focused on the

68 absolute and relative dimensions of massive-based points from Central Europe. This

69 approach allowed him to identify use and resharpening as primary converging processes

70 that produce morphometric variability on the distal portion of the implements, however, it

71 failed to address the shape variability of the proximal portion of these objects. Other

72 researchers investigated variation in both the shape and size of archaeological specimens

73 (Albrecht et al., 1972; Clément and Leroy-Prost, 1977; Knecht, 1991). However, they

74 searched for patterns of variation through the analysis of the implements' general outline

75 in an attempt to identify the specific forms reproduced by the makers of the Aurignacian

76 projectile points. Consequently, the results obtained necessarily conflated a minimum of

77 two sources of variation, i.e., the range of forms of newly manufactured points and the

78 morphometric variability resulting from their utilization. Shape variation in tools could be

79 caused by a variety of processes. Therefore, given the anisotropic properties of osseous

80 material, one cannot assume every portion of a point would be equally affected by these

81 processes (see below).

82 From an analytical standpoint, with the exception of the works by Turk (2002,

$832003,2005)$, these studies were carried out prior to, or during, the development of

84 modern landmark-based geometric morphometrics (Bookstein, 1989, 1991, 1996, 1997;

85 Moyers and Bookstein, 1979). The theoretical and methodological advances made in this

86 field of investigation over the last two decades now bring forth new prospects to reassess

87 the morphometric variability of Aurignacian osseous projectile points with the aim of

88 identifying the shapes that were reproduced by the prehistoric populations. In the present

89 paper, the concept of shape modularity (Adams, 2016; Klingenberg, 2008, 2009;

90 Klingenberg and Marugán-Lobón, 2013) is used to analyze the outline of Aurignacian

91 split- and massive-based points from 38 European sites. This concept is useful to identify

92 the point of demarcation between distinct techno-functional units, or components, on the

93 shape of an implement of composite technology. The morphometric variability of each 
94 component can then be interpreted as a result of functional and/or stochastic processes in

95 the light of technological and experimental data. Focusing on the component that is

96 mainly affected by stochastic processes allows the identification of eight proximal shapes

97 for split-based points and two proximal shapes for massive-based points. The geographic

98 distribution of these shapes is investigated to assess patterns of regionalization.

\section{Research background}

101 Distinguishing between groups of cultural artefacts constitutes an important goal in 102 archaeological studies. Over the past decade, specialists of lithic technologies have

103 invested much effort in investigating patterned variation in the morphology of stone tools

104 by applying landmark-based geometric morphometrics methods to their studies (e.g.,

105 Archer and Braun, 2010; Buchanan et al., 2013; Buchanan and Collard, 2010a, 2010b;

106 Cardillo, 2010; Charlin and González-José, 2012; Costa, 2010; Lycett et al., 2010; Lycett

107 and von Cramon-Taubadel, 2013; MacLeod, 2018; Petř́ík et al., 2016; Picin et al., 2014;

108 Shott and Trail, 2010; Thulman, 2012). However, borrowing a tool conceived for

109 evolutionary biological studies and applying it to the study of material culture necessarily

110 requires some adaptations. To make sense of the patterned variation of a given tool type,

111 studies on shape variability should be carried out by taking into consideration the relevant

112 technological and experimental data which inform us on the processes that generate

113 variation in material culture. Throughout the present section, Aurignacian osseous

114 projectile points are used as a case study to exemplify how the integration of such

115 technological, experimental, and morphometric data can be achieved. However, the logic

116 outlined below can be adapted to other prehistoric tool types. First, the challenges

117 inherent to applying geometric morphometrics methods to analyze tools with a

118 geometrically simple outline are presented. It is followed by a discussion on the

119 technology of composite projectile to highlight the importance of using the concept of

120 shape modularity to quantitatively identify the point of demarcation between distinct

121 techno-functional units on projectile armatures. Then, experimental data on the use and

122 efficiency of prehistoric projectile technology is reviewed to target the techno-functional

123 unit that is more likely to retain the original shapes reproduced during the manufacture of 
124 the points. Finally, the factors causing shape variation are summarized as well as the

125 criteria that allow identifying their respective effect on the archaeological record.

126 Applying geometric morphometrics methods to the analysis of Aurignacian osseous

127 projectile points constitutes a real challenge given their simple outline and the

128 fragmentary state of most specimens. On the one hand, the simple outline limits the

129 number of Type I landmarks (Bookstein, 1991; Mardia and Dryden, 1989) that can

130 possibly be recorded, i.e., the loci equivalent to anatomical features present on every

131 outline such as the distal tip, the basal end, or the points delimiting the maximum width

132 of the artefact. In most cases, only the latter two landmarks are available, i.e., the two

133 landmarks that are placed on either side of the point of maximum width (see Lycett et al.,

1342006 for a discussion on the lack of Type I landmarks on archaeological artefacts).

135 However, their position at either end of one of the tool's major axis, i.e., the maximum

136 width, prevents the precise definition of homologous sliding semi-landmarks (Perez et al.,

137 2006) along the outline of the point. On the other hand, given that most specimens are

138 damaged, with distal and/or proximal fractures, it is not possible to accurately estimate

139 the percentage of completeness of a point. Consequently, both semi-landmark methods

140 (Bookstein, 1997) and Fourier transform methods (Haines and Crampton, 2000) cannot

141 be used for simple shape comparison.

142 Some studies have explored the possibility of digitizing the tool's shape by

143 recording landmark coordinates from a polar grid superimposed on photographs of the

144 artefacts and centered at the intersection of the implements main axes, i.e., the maximum

145 length and width (Archer and Braun, 2010; Lycett et al., 2010; Lycett and von Cramon-

146 Taubadel, 2013). The use of a polar grid ensures the homology of each landmark

147 regardless of variation in the size or the shape of the artefact. This method confers a

148 substantial advantage as it allows the quantification of the amplitude at which a shape

149 varies in any direction from a given centroid. The problem that arises is how variation

150 resulting from the use and repair of an object can be distinguished from the forms

151 originally replicated during its manufacturing process. Such distinction requires a prior

152 understanding of the various constraints inherent to the technological project that led to

153 the production of the tool and the context in which it was used. 
The manufacture of composite projectile technology requires the production and 155 assemblage of tightly fitted parts designed to fulfill a number of distinct functions. For 156 instance, the proximal end of a shaft must be shaped to ensure it adequately grips the 157 launching device to allow the proper transfer of projecting forces to the projectile when 158 launched. Meanwhile, the distal end of the shaft must be carved to facilitate the hafting of 159 an armature. It should ideally be streamlined and smoothed in order to reduce friction 160 during the penetration of the projectile into the prey, while remaining solid enough to 161 withstand the forces of impact when meeting a target. A minimum of two techno162 functional components can be segregated on the armature of a composite projectile. First, 163 the proximal portion must be shaped to allow the hafting of the implement, and to 164 withstand and transfer the forces of impact from the armature to the shaft of the 165 projectile. When implements are made in advance, the standardization of their proximal 166 portion eases the replacement of damaged armatures as long as the shaft remained intact 167 during the use of the projectile. Second, the distal portion must be given a form fit to 168 pierce the skin of the prey and to induce a lethal wound to the animal. Technological data 169 on the manufacture of osseous projectile points are useful to estimate the point of 170 demarcation between these two techno-functional components on Aurignacian armatures. 171 Indeed, traces of the final stages of their manufacture tend to overlap at the point of 172 maximum width, the final shaping of the distal portion being subsequent to that of the 173 proximal one (Doyon, 2017b; Knecht, 1997; Liolios, 1999). This observation indicates 174 the proximal and distal portions of the implements were shaped separately, and therefore, 175 it suggests the makers of Aurignacian projectile points conceived their osseous hunting 176 implements as objects combining two functionally distinct, yet complementary, 177 components, each subjected to their own shaping imperatives. The point of maximum 178 width likely corresponds to the point of demarcation between these two techno-functional 179 units. This assumption can be tested by borrowing a central concept from evolutionary 180 biology and geometric morphometrics, i.e., shape modularity (Klingenberg, 2008, 2009; 181 Klingenberg and Marugán-Lobón, 2013).

182 Shape modularity is founded on the 'theory of nearly decomposable systems, in 183 which the interaction amongst the subsystems are weak, but not negligible' (Simon, 184 1962, p. 474). In biology, modularity refers to cases where the landmark configuration of 
185 an organism can be split into subsets of landmarks, or modules, and where patterns of

186 variation are unevenly distributed between subsets; covariation is greater for landmarks

187 belonging to a given module while being weaker for landmarks across modules

188 (Klingenberg, 2008, 2009; Klingenberg and Marugán-Lobón, 2013). These modules are

189 usually interpreted as a consequence of developmental, functional, or evolutionary

190 processes. Likewise, from a technological perspective, the components of a modular

191 structure should be functionally distinct and their variability is expected to be relatively

192 independent from one another. Shape modularity has seldom been solicited in

193 archaeological studies of material culture. Following Cardillo's (2010) suggestion that

194 lithic points could be divided into a set of modules based on morphological or

195 technological criteria, González-José and Charlin (2012) used shape modularity to assess

196 functional variability of lithic points from Late Holocene contexts in southern Patagonia,

197 while de Azevedo et al. (2014) highlighted differences in the patterns of maintenance of

198 these same points according to their function. In the present paper, the first application of

199 shape modularity in osseous technologies is presented for two types of Aurignacian

200 projectile points, i.e., the split- and massive-based points. The aim is to identify the

201 shapes that were considered fit for hunting and reproduced by the makers of these

202 technologies. Such investigation requires the identification of the techno-functional unit

203 that is more likely to have retained the original shape reproduced during the manufacture

204 of an armature in spite of the various episodes of use, damage, reshaping and recycling it

205 underwent prior to being lost or discarded at a site.

206 Experimental data on the use and efficiency of osseous projectile technologies

207 tends to demonstrate that the distal portion of an osseous armature is more prone to

208 damages resulting from its utilization than the proximal portion of the object (Bradfield,

209 2013; Bradfield and Brand, 2013; Doyon and Katz Knecht, 2014; Knecht, 1991, 1997;

210 Newcomer, 1974; Pétillon, 2006). This differential breakage pattern is best explained by

211 the mechanical properties of the raw material itself (Christensen, 2004; Doyon and Katz

212 Knecht, 2014; Knecht, 1991, 1997; Newcomer, 1974) and has implications on how to

213 study the shape of these tools. Assuming that most Aurignacian projectile points

214 discarded at sites had reached their optimal threshold in terms of perceived utility and

215 efficiency (Doyon, 2017b, p. 233), the original rules of production guiding the shaping of 
216 the implements' distal portion are likely to have disappeared from the archaeological

217 record. Some archaeological specimens, however, also attest to the repair of the damaged

218 proximal portion and the recycling of fragmented points (Tejero, 2014). The effects of

219 the maintenance of split-based points, for example, are mainly visible on their cross-

220 section morphology, i.e., the original elliptical section becomes more biconvex, while

221 their maximum width and thickness remain more or less the same as these variables were

222 likely determined by the size of the - presumably wooden - shaft to which they were

223 attached. Furthermore, the maintenance of a point's proximal portion may cause its edges

224 to become slightly asymmetrical, albeit not sufficiently deformed to make the original

225 outline unrecognizable (Tejero, 2016). Therefore, the search for original shapes should

226 focus on the hafted proximal end of the point, as this portion is less likely to have

227 undergone substantial modifications over time (see Ahler and Geib, 2000; Smith and

228 DeWitt, 2017; Thomas et al., 2017 for similar arguments in the case of Paleoindian fluted

229 points from North America).

230 Apart from the extent of reworking it underwent, the proximal shape of

231 Aurignacian projectile points could vary due to the type of raw material used for their

232 manufacture, the alteration incurred following their post-deposition, the intended function

233 of the tool, or a number of learning and population-regulated processes, e.g., socially

234 shared rules of production, skill, copying errors, and cultural drift. Associated evidence

235 from the archaeological record can guide the interpretation of patterned variations as a

236 result of either of these processes; each factor is reviewed below. The mineral and

237 organic composition as well as the structure of the osseous material vary between antler,

238 bone, and ivory (see Christensen, 2004; Knecht, 1991 for a review). This variation could

239 impose some limitations on the sequence of techniques that is applied during the

240 manufacture of a particular tool type. Differences in manufacturing behavior could also

241 be, in some cases, a proximal factor that underlies differences in shape of a given tool

242 type (e.g., Schillinger et al., 2017). Therefore, one should seek for correlations between

243 raw material and the tool type, its shape, or both to assess its effect on morphometric

244 variability. Post-depositional alterations could either result in the damage or the

245 deformation, i.e., compression or bending, of the outline of a bone tool given the

246 anisotropic properties of this raw material. Ideally, these alterations should be identified 
247 and the specimens, or the landmarks, affected by this process should be removed from an 248 analysis that aims to document the patterned variation of newly made tools. If function is 249 a primary driver for differences in weapon form, one should expect to find discrete 250 associations between the shape of the tool and either the type of prey that was hunted, the 251 ecological niches in which the points were recovered, or some evidence of its use in 252 different tasks such as penetrating, slicing, or cutting. However, with regard to this last 253 factor, and unlike their lithic counterparts, the edges of osseous points do not have 254 lacerating properties. The smooth surfaces of Aurignacian implements suggest their 255 intended function was primarily to pierce the skin and penetrate sufficiently deep into the 256 prey to perforate the internal organs and cause a lethal hemorrhage (Knecht, 1991, 1997).

257 Therefore, in the present study, functional associations will only be sought between the

258 artefact shape and the type of prey as well as the ecological niches in which the armatures 259 were used.

260 Included amongst the learning and population regulated processes are socially 261 shared rules of production (Lycett and von Cramon-Taubadel, 2015; Schillinger et al., 262 2014), skill (Eerkens, 2000; Ingold, 2002; Minar, 2001), copying errors (Eerkens and 263 Lipo, 2005; Gandon et al., 2014; Hamilton and Buchanan, 2009; Schillinger et al., 2014), 264 and cultural drift (Binford, 1963; Koerper and Stickel, 1980). Socially shared rules of 265 production can be identified through the occurrence of a weapon form at multiple sites of 266 comparable age. The geographic distribution of these forms would signal the territory 267 inhabited by the populations amongst which these rules were shared. Differences in skill 268 are more likely to result in the variation of a given shape rather than in the long-lasting 269 production of an altogether new weapon form. Copying errors, on the contrary, are 270 cumulative by nature. If this process is in action, one should expect to identify gradual 271 trends in time from an original to a new tool shape. Likewise, if cultural drift is 272 responsible for the patterned variations, gradual trends should be observed in both space 273 and time. Lastly, morphological differences could potentially be the result of temporal 274 drift (e.g., Rigaud et al., 2015, 2018). In this scenario, stratified sites should testify to the 275 appearance and disappearance of specific artefact forms through time. However, 276 chronology, in and of itself, does not provide an explanation as to how and why 277 morphological variability was introduced in the production sequence. Therefore, 
278 temporal drift must be explained by other processes such as copying errors, cultural drift 279 or changes in the favored rules of production.

\section{Materials and Methods}

The sample considered in the present study comes from 38 sites and comprises 499 projectile points (294 split- and 205 massive-based points; Tab. 1). The technological, morphometric, and use-wear data were collected on the archaeological specimens in the course of two doctoral projects (Doyon, 2017b; Knecht, 1991). The first data collection was carried out by Heidi Katz Knecht in 1987-1988 and focused on assemblages from Western Europe. The second was conducted by myself in 2015 and aimed to complement Katz Knecht's observations to obtain a continental perspective of the phenomena. Therefore, assemblages from Southern and Central Europe were targeted. Heidi Katz Knecht provided access to the data she collected by sharing recording sheets and photographs of the archaeological specimens. This information was digitized in high resolution and is now curated on the server of the Hominin Dispersal Research Group at the Department of Anthropology of the University of Montreal. Both data collections

295 Complete points and fragments were studied during this phase of the projects. In an effort

296 to maximize the sample size considered in the present study, all specimens retaining their 297 point of maximum width were selected.

298 A 36-segment polar grid was superimposed on photographs of the plan view of the 299 superior aspect of the artefacts, i.e., the aspect where the antler spongiosa, or traces of it, 300 is not present, in order to record the landmarks that summarize their shape configuration.

301 The origin of this grid was aligned at the intersection between the main axes of the tool,

302 i.e., the maximum length and width (Fig. 1a). Following the superimposition of the grid, 303 the digitization of the shape configuration consists of recording 36 landmarks for each

304 specimen. The use of photographs to record landmarks implies the shape of the objects is

305 modeled in only two dimensions. The comparison of 3-dimensional shapes from 2-

306 dimensional landmark configurations can indeed result in the loss of information on the

307 overall morphometric variability. However, this loss is not statistically significant for

308 almost flat objects (Velhagen and Roth, 1997), which is the case for Aurignacian osseous 
309 projectile points. Therefore, the primary assessment of the morphometric variability of 310 these implements focused on the outline of the tool. The armature's thickness was later 311 considered in the clustering method as a means to identify the proximal shapes

312 reproduced in the manufacture of projectile points (see below). Landmarks were recorded

313 at the intersection of a grid segment and an intact portion of the point's outline in order to

314 de facto rule out variability that could be attributed to post-depositional processes. The

315 first landmark corresponds to the right end point of the maximum width and the 35

316 remaining landmarks are consecutively recorded clockwise from one grid segment to the

317 next. The same procedure was carried out for the damaged points with the exception that

318 missing landmarks were given [NA,NA] coordinates in the *.nts file where the shape

319 configurations were saved (Fig. 1b). The data was subsequently uploaded in R-CRAN (R

320 Development Core Team, 2008) using the 'geomorph' package for morphometric

321 analysis (Adams et al., 2016; Adams and Otárola-Castillo, 2013). No attempt to

322 interpolate missing landmarks was undertaken in the present study. However, the sample

323 size varies from one analysis to the next. For each analysis, the specimens included are

324 those with known coordinates for each landmark considered (see below).

325 Shape can be broken down into two constitutive elements: the geometry of an

326 object, synthesized or modeled from the landmarks' configuration of the outline, and its

327 size. To compare distinct shape configurations, they must be aligned using the

328 Generalized Procrustes Analysis (GPA) (Fig. 1c). This analysis consists of three

329 procedures. First, it translates the configurations to center them on a common centroid.

330 Second, it iteratively rotates the landmark constellations to ensure their adequate

331 alignment. Finally, the shape configurations are iteratively scaled to the same centroid

332 size in order to minimize the standard error between the various configurations and the

333 mean shape, i.e., a hypothetical shape for which each landmark coordinate equals the

334 average locus of the corresponding landmarks in a given sample. This scaling nullifies

335 the effect of size when comparing shapes and allows the analysis to be performed solely

336 on the object's geometry (Rohlf and Slice, 1990; Slice, 2005; Zelditch et al., 2004). To

337 ensure comparability, a GPA must be performed every time a subsample is selected, e.g.,

338 when the analysis is conducted solely on split- or massive-based points as opposed to

339 both types simultaneously. This step is required to quantify how a given shape varies 
340 relative to the others included in the subsample. From the GPA, two variables can be 341 extracted. The first corresponds to the mean shape configuration and the second is the 342 specimens' centroid size, i.e., the sum of squared distances of a series of major landmarks 343 to their common centroid (Bookstein, 1991).

$344 \quad$ Testing for shape modularity implies calculating a covariance ratio $C R$ of a 345 hypothetical modular configuration and comparing it to a number of randomly generated 346 ones. Non-parametric testing allows for the quantification of $C R$ and its associated $p$ -

347 value. The null hypothesis of an equal variation in the covariation matrix is rejected at $\alpha$ $348=0.05$ when $C R$ is lower than 1 (Adams, 2016). The rejection of the null hypothesis 349 entails the techno-functional components of a point should be studied separately in order 350 to assess their respective contribution to the overall morphometric variability. For this 351 test, only complete specimens with data for the 36 landmarks are selected ( $n=111$; split352 based points: $n=64$; massive-based points: $n=47$ ).

353 After defining the limits of each techno-functional component (Fig. 2d), a principal 354 component analysis (PCA) allows for the general assessment of their morphometric 355 variability by projecting the specimens on Kendall's tangential shape space (Slice, 2001).

356 PCAs are produced for each techno-functional component separately. All the landmark 357 coordinates of a given techno-functional component, i.e., the proximal or distal portion of 358 a point, had to be known for a specimen to be included in the corresponding PCA.

359 Consequently, the sample size for the PCA of the proximal portion of the points $(n=285$; 360 split-based points: $n=139$; massive-based points: $n=146$ ) differs from that of the distal 361 portion ( $n=111$; split-based points: $n=64$; massive-based points: $n=47)$. PCA plots are 362 produced and the relative warps for each principal component are extracted and 363 illustrated.

364 Finally, a focus on the proximal portion of the points aimed to identify clusters of 365 armatures similar both in shape and in size. To this end, the values for the first two 366 principal components of the morphometric variability and the centroid size of the 367 specimens were extracted from the corresponding PCA and combined as dependent 368 variables in a new PCA, along with the point's thickness perpendicular to the maximum 369 width. The proximal length and maximum width, the geographic coordinates, the name of 370 the sites, and the name of the region to which these localities belong were added in the 
371 PCA as quantitative and qualitative independent variables. The independent variables had 372 no weight on the PCA; they were only included to quantitatively and qualitatively

373 characterize the shape clusters (see below). A hierarchical clustering technique

374 complemented with a $k$-mean aggregation procedure was performed with the results of

375 this second PCA in R-CRAN (R Development Core Team, 2008) using the 'FactoMineR'

376 package (Lê et al., 2008). A non-parametric test to compare the relative proportions was

377 computed to characterize the shape clusters and to find sites or regions where they are

378 over- or underrepresented. This test follows the hypergeometric distribution $H\left(\mathrm{n}_{\mathrm{c}}, \mathrm{n}_{\mathrm{m}} / \mathrm{n}, \mathrm{n}\right)$,

379 where $n$ is the total sample size, $n_{m}$ is the sample size for a given site or region and $n_{c}$ is

380 the sample size for a given cluster (Husson et al., 2011). The data and R code used in the

381 present research is available upon request.

\section{Results}

384 In the sample considered for the present study, more than one fifth of the points are 385 complete (split-based points: 21.8\%; massive-based points: 22.0\%; Tab. 1). Proximal and

386 distal damages are respectively present on $18.3 \%$ and $27.0 \%$ of split-, and $1.9 \%$ and

$38747.5 \%$ of massive-based points (Tab. 2). Both proximal and distal damage was recorded

388 on $47.0 \%$ of split- and $41.9 \%$ of massive-based points. The remaining portion of the

389 sample shows lateral damage, sometimes in combination with proximal and/or distal

390 damage (split-based points: 7.8\%; massive-based points: 8.8\%). Aside from three

391 specimens, i.e., two made of bone and one made of ivory, all split-based points are made

392 of antler. Massive-based points were predominantly produced from antler (73.1\%) but

393 also from bone (21.5\%) and ivory (5.4\%). In Western Europe, all massive-based points

394 were made of antler with the exception of one specimen made of bone from La Ferrassie.

395 In Central Europe, the three raw materials were used for the manufacture of this tool

396 type. However, points made of bone predominantly come from Potočka zijavka and those

397 in ivory are mostly found at Mamutowa.

398 The modularity test (Fig. 2) produces significant results for both split- (observed

$399 C R=0.885 ; p=0.001$ ) and massive-based points (observed $C R=0.92 ; p=0.038$ ). These

400 results indicate the patterns of covariation are unevenly distributed between the proximal

401 and the distal portions of complete specimens, which provide quantitative support to 
402 technological and experimental observations. As suggested by the overlap of the traces of 403 manufacture, the maximum width is identified as the point of demarcation between these 404 two techno-functional components (Fig. 1d). The maximum width itself belongs to the 405 distal component of the armature. The uneven distribution of the patterns of covariation 406 between both techno-functional units implies different processes were likely responsible 407 for their respective variability. In order to avoid conflating these factors in the following 408 analysis, shape variation for each techno-functional unit is addressed separately.

The first two principal components explain $95.16 \%$ of the total variation of the points' proximal portion (Fig. 3a). They relate to the maximum width relative to the

412 the degree of lateral convergence (PC2: 9.24\%). The lateral asymmetry of the proximal 413 portion of the points only accounts for $1.93 \%$ of the total variation as reflected on the 414 third principal component. Both projectile point types significantly differ from one 415 another along the first two principal components. When the raw material is taken into 416 account (Fig. 3b), no statistically significant differences were observed for the principal 417 components values of massive-based points' proximal portion. The values obtained for 418 armatures in bone or in ivory are comprised within the range of variation observed for 419 those made of antler.

420 For the distal portion of the points, the first two principal components explain $42195.23 \%$ of the total variation (Fig. 4a). The first principal component synthesizes the 422 maximum width relative to the distal length combined with the morphology of the tip 423 (PC1: 91.22\%), while the second relates to the lateral asymmetry of the distal portion 424 (PC2: 4.01\%). Both types are considerably overlapping, although split-base points tend to 425 have a smaller distal length relative to their maximum width compared to massive-based 426 points. Specimens made of bone or ivory display principal components' values within the 427 range of variation observed for antler armatures (Fig. 4b).

428 The hierarchical clustering procedure identifies eight shape clusters (S01 to S08) 429 for split-based points (Fig. 5-6). Specimens assigned to distinct clusters differ both in 430 terms of their size and their shape. Seven shape clusters (M01 to M07) are identified for 431 massive-based points when applying the same method (Fig. 7-8). However, with the 432 exception of the specimen assigned to the cluster M04, the implements belonging to the 
433 six other shape clusters show substantial morphological overlap (Fig. 7b), and only differ

434 from one another when the size of the armatures is considered (Fig. 7c).

435 The geographic distribution of the shape clusters at a continental scale shows

436 contrasting patterns when both projectile point types are compared (Tab. 4-5). The

437 proximal shapes identified for split-based points are found over vast regions of Europe.

438 However, five of these shapes are relatively more abundant in some regions (Tab. 4).

439 This is the case for S01 in Cantabria and in the Western Pyrenees region, for S02 in the

440 Carpathian Mountains region, for S05 in the Meuse watershed and the Swabian Jura, for

441 S06 in the Eastern Pyrenees region, and for S07 in Southwest France. This

442 regionalization pattern is also observed in the absence of specimens assigned to the

443 proximal shape S05 in Southwest France. At a continental scale, S04 is absent from the

444 Meuse watershed, the Swabian Jura, and the Western Carpathian while being present in

445 all the other regions to the South.

446 In contrast, the proximal shapes identified for massive-based points are

447 predominately aggregated locally or regionally. Some forms are indeed found at a single

448 site such as M06 in Willendorf and M07 in Mamutowa, or at a number of sites from the

449 same region such as M03 in Blanchard, La Ferrassie and Les Vachons, or M04 in Vindija

450 and Mladeč. As a general rule, when a proximal shape of a massive-based point is

451 overrepresented in Western Europe, it is usually underrepresented in Central Europe, and

452 vice versa (Tab. 5).

\section{Discussion and Conclusion}

455 The present study represents a first attempt to apply landmark-based geometric

456 morphometrics and use the concept of shape modularity to analyze the morphometric

457 variability of osseous projectile technology. The results obtained from the shape

458 modularity test supports the idea that Aurignacian populations conceived their osseous

459 armatures as tools combining two distinct, yet complementary, components fulfilling

460 different functions. The shaping of either component clearly followed specific guiding 461 principles. While similarities are observed for the shape of the artefacts' distal portion, 462 both types differ significantly with regard to the morphology of their hafted portion. The 463 application of geometric morphometrics to explore the variability of the hafted portion 
464 allows the identification of the proximal length relative to the maximum width as the 465 principal component of their shape variation. This result has important implications for 466 our understanding of Aurignacian osseous projectile technology. If the points' maximum 467 width and thickness were constrained by the cross-section's dimensions of the wooden 468 shaft on which they were attached (Tejero, 2014, 2016), the points' proximal length, and 469 their proximal morphology, likely varied based on the conception prehistoric artisans had 470 of a suitable hafting mechanism. Reworking of damaged proximal portions seems only to 471 have marginally affected the morphology of the points as attested by the low percentage 472 of variation resulting from lateral asymmetry.

473 When both the objects' size and geometry are taken into consideration, eight shape 474 clusters for split- and seven for massive-based points can be described. Since the split475 based point clusters differ both in terms of size and shape, we can infer that their makers 476 tried to reproduce one of eight distinct proximal shapes when manufacturing an armature. 477 On the contrary, with the exception of M04, the clusters identified for massive-based 478 points are similar in shape but distinct in size. This result suggests the makers of this tool 479 type likely aimed to reproduce one of two proximal shapes, one of which could take a 480 number of variants. It should be stressed that the number of proximal shapes identified 481 per tool type in this study must be considered a minimum value, which may increase in 482 future studies conducted on an enlarged sample. The development of a method to 483 accurately estimate the coordinates of missing landmarks could also result in an increased 484 number of proximal shapes.

485 The geographic distribution of split- and massive-based points' proximal shapes 486 highlights conspicuous differences that are best understood when two technological 487 aspects are considered, i.e., raw material selection and the complexity of the reduction 488 sequences for the manufacture of these implement types. The split-based points found in 489 the archaeological record were almost exclusively made of antler. Given its higher 490 percentage of organic matrix compared to bone or ivory, its microstructural organization, 491 and its ensuing mechanical properties (Albrecht, 1977; Christensen, 2004; Currey, 1979, 492 1984, 1999, 2002; Knecht, 1991), antler is more suitable for the manufacture of the 493 proximal split than the two other raw materials. This step of the reduction sequence 494 constitutes a critical moment (sensu Lemonnier, 1976) in the manufacture of this tool 
495 type, and it requires a certain level of mastery. Indeed, failure to produce a proximal split

496 would result in the loss of a suitable blank, or of a substantial portion of it, for the

497 manufacture of a point. Use-wear studies combined with experimental replications

498 suggest the production of a proximal split could be achieved through the application of a

499 number of processes such as cleaving the blank (Knecht, 1989, 1991, 1993) or the flexion

500 of the blank subsequent to its incision (Nuzhnyi, 1998; Tartar and White, 2013). The

501 selection of a unique raw material to be transformed following a given sequence of

502 techniques in order to achieve particular morphologies that show patterns of

503 regionalization over vast territories suggests that somewhat strict rules of production

504 guided the Aurignacian makers of split-based points. On the contrary, massive-based

505 points could be made of antler, bone, or ivory, and the shaping of their hafted proximal

506 portion can be achieved simply by scraping. Furthermore, the geographic distribution of

507 the proximal shapes identified in the present study is mainly characterized by their

508 regional or local aggregation. Together, these observations indicate an increased

509 flexibility in the rules of production of this tool type compared to those of the split-based

510 points.

511 If utilization and resharpening of the points account for the morphometric

512 variability of their distal portion (Doyon and Katz Knecht, 2014; Liolios, 1999; Tejero,

513 2014; Turk, 2002, 2003, 2005), other factors responsible for the patterned variations

514 observed on the proximal portion of Aurignacian osseous armatures must be considered.

515 Raw material availability could explain the predominance of bone points at Potočka

516 zijavka and of ivory points at Mamutowa. Indeed, the numerous cave bear remains at

517 Potočka zijavka indicate this locality served as hibernating den for this animal. It

518 remains, however, difficult to assess if Aurignacian groups visited this site to kill

519 hibernating prey at a time when they were most vulnerable (e.g., Withalm, 2004), or if

520 they exploited carcasses of animals that died of natural causes. In the case of Mamutowa,

521 this site is located in a region where mammoth hunting and exploitation by Aurignacian

522 populations are documented (Vercoutère and Patou-Mathis, 2010). Nonetheless, Potočka

523 zijavka yielded specimens with proximal shapes highly similar to those produced in

524 antler found at La Ferrassie. On the other hand, although M07 was exclusively found at

525 Mamutowa, this shape corresponds to a variant of one of the main proximal shapes 
526 identified for massive-based points. As mentioned above, these variants mainly differ

527 when the implement's size is considered. Consequently, in addition to having an effect on

528 the type of projectile point to be manufactured, it appears the raw material mainly

529 determined the size of massive-based points but had little bearing on their proximal

530 morphology.

531 It has been suggested that differences in function could explain differences in

532 weapon forms (Tartar and White, 2013). This hypothesis usually conflates a number of

533 elements, i.e., function could relate to the type of projectile onto which the armatures

534 were hafted, the type of prey targeted by the hunters, or the ecological niche in which the

535 projectiles were used. It is generally accepted that Aurignacian osseous projectile points

536 were hafted on spears to be launched with spear-throwers, although some researchers

537 suggested the smallest split-based points could have been hafted on arrows (Odar, 2011;

538 Otte, 2014). Given that the other components of Aurignacian projectile technology such

539 as the presumably wooden shaft and/or foreshaft are absent from the archaeological

540 record, questions relating to the type of the projectile on which these armatures were

541 affixed and their mode of propulsion remain open. Future ballistic experiments combined

542 with morphometric analysis could potentially provide informative clues as to the type and

543 extent of damages resulting from the use of different hunting technologies. Regardless of

544 the type of projectile, zooarchaeological evidence indicates the makers of the

545 Aurignacian material culture were efficient hunters able to adapt their subsistence

546 behaviors to a variety of biotas. Horses were one of the favored prey, but they also

547 exploited other animals available in the many ecological niches of the European continent

548 at the time (Vercoutère and Patou-Mathis, 2010 for a comprehensive review). The

549 geographic distribution of the proximal shapes of Aurignacian osseous projectile points

550 seems not to be limited to a particular niche. It therefore seems unsubstantiated, given the

551 information available at this time, to explain the morphometric variability of a particular

552 tool type solely with functional imperatives surrounding the use of this technology.

553 The effects of learning and population regulated processes on the morphometric

554 variability of split- and massive-based points are somewhat difficult to assess at this

555 point. The three principal components of variation identified for the proximal portion of

556 the implements in the present study leave unexplained only a small percentage of the 
557 overall variability. Differences in skill could probably be a factor that caused this

558 variation. The biggest challenge, however, relates to our abilities to assess the impact of

559 population-regulated processes and temporal drift on the morphometric variability of

560 either tool types. Establishing a precise chronology for the presence of each proximal

561 shape is difficult since the Aurignacian technocomplex occurred at a time that is near the

562 limit of applicability of ${ }^{14} \mathrm{C}$ dating methods. Yet, Aurignacian osseous projectile points

563 were often found at localities that were visited for relatively short periods of time. This is

564 especially true for the sites in Southern and Central Europe, i.e., Provence-Liguria,

565 South-central Europe, and Western Carpathians, where archaeological evidence suggests

566 they mainly served as hunting camps (Doyon, 2017a, under review), or were recurrently

567 occupied on a seasonal basis (Adams, 2009). Nevertheless, evidence from stratified sites

568 in southwestern France that attest to lengthier occupations, e.g., abris Castanet and

569 Blanchard, La Ferrasie, and Isturitz, suggests the contemporaneous occurrence of

570 multiple proximal shapes in their archaeological horizons, which could be an argument in

571 favor of the co-occurrence of micro-traditions within the Aurignacian (see Riede and

572 Pedersen, 2018 for a similar phenomenon within the Hamburgian culture). However,

573 more contextual and chronometric data are required to state with confidence if this

574 pattern indeed represents contemporaneity or if it is merely the result of a palimpsest of

575 occupations.

576 Despite the limitations imposed by the archaeological record, which prevent us

577 from precisely distinguishing the relative effects of the aforementioned processes on the

578 morphometric variability of Aurignacian osseous projectile points, the ethnographic

579 literature highlights the fact that the adoption of a particular hunting technology results

580 from a number of complex decisions, and that the knowledge surrounding the

581 manufacture and use of these technologies is socially shared (Churchill, 1993; Ellis,

582 1997). This knowledge includes the type of projectile that should be manufactured, the

583 ways in which they should be used, but most importantly the technological sequence

584 leading to their production. It should be stressed that variations in the proximal shape of

585 Aurignacian armatures perhaps originated from minute differences in the manufacturing

586 processes of the points, i.e., differences in how an armature should be made in order to be

587 considered fit for hafting and hunting prey, rather than from the imposition of a mental 
template on the osseous material (sensu Schillinger et al., 2017). In this sense, the

589 proximal portion of split- and massive-based points seems to have preserved clues

590 allowing us to identify the socially shared rules of production that guided their

591 manufacture, and therefore, highlights micro-traditions within the Aurignacian

592 technocomplex similar to those recognized form Middle Stone Age contexts in Africa

593 (Archer et al., 2016) and from Hamburgian contexts in northern Europe (Riede and

594 Pedersen, 2018). The differences in the geographic distribution of the proximal shapes of

595 split- and massive-based points are surely informative of population dynamics such as

596 coalescence and fragmentation, similar to those documented from southern Africa

597 throughout the MIS5 to the MIS2 (Mackay et al., 2014). If this is the case, the variability

598 in the proximal shape of massive-based points combined with their respective geographic

599 distribution likely signal convergent solutions to a same problem, i.e., producing a

600 projectile point with a proximal portion that can be easily be shaped without risking to

601 damage the blank in the process. On the other hand, the pattern described for split-based

602 points probably implies more generalized inter-regional group interactions either through

603 the movement of individuals over long-distance or the transfer of complex knowledge

604 across long-distance through short chains of interaction (e.g., Lombard and Högberg, 605 2018).

606 The results and discussion presented here set forth a previously unexplored research 607 perspective for studies on the European Early Upper Palaeolithic. Research conducted 608 thus far on the identification of the social groups within the Aurignacian metapopulation

609 and the extent of their interactions relied on multiple sources of evidence such as the 610 distribution of ornament types (Vanhaeren and d'Errico, 2006) and the technological

611 organization of their manufacture (Heckel, 2018), the geographic distribution of

612 manufacturing techniques for lithic (Bon, 2002; Michel, 2010; Teyssandier, 2007) and

613 bone technologies (Albrecht et al., 1972; Goutas and Tejero, 2016; Knecht, 1991; Liolios,

614 1999; Tartar and White, 2013), bladelet morpho-technology (Le Brun-Ricalens and

615 Bordes, 2007; Riel-Salvatore and Negrino, 2018), as well as lithic raw material

616 procurement strategies (Caux, 2015, 2017; Féblot-Augustins, 1997, 1999, 2009; Grimaldi

617 et al., 2014; Porraz et al., 2010; Riel-Salvatore and Negrino, 2009). By applying

618 geometric morphometrics and the concept of shape modularity to the analysis of 
619 Aurignacian osseous projectile points, it is now possible to add the morphometric

620 variability of their proximal portion to this list of evidence that can serve to identify

621 prehistoric group membership. Future research conducted with the aim of finding

622 correlations between these different proxies will undoubtedly be successful in shedding

623 light on the extent of interactions of past populations at a turning point of the European

624 Palaeolithic.

\section{Acknowledgment}

627 I wish to thank Ariane Burke, Francesco d'Errico, and Heidi Katz Knecht for their

628 constant guidance throughout my doctoral research. Sincere thanks are given to the 16

629 Museums and Academic Institutions where the material was studied. The Social Sciences

630 and Humanities Research Council of Canada funded this research (Joseph-Armand

631 Bombardier CGS doctoral grant \#752-2014-1730) as well as the China/Shandong

632 University International Postdoctoral Program, the Department of Anthropology and the

633 Faculté des Études supérieures et post-doctorales of the Université de Montréal, the

634 Hominin Dispersal Research Group, and the UMR5199 - PACEA, a partner of the

635 LaScArBx, a structure funded by the ANR $n^{\circ}$ ANR-10-LABX-52. I acknowledge the

636 valuable feedback from Stephen J. Lycett and the anonymous reviewers that allowed

637 improving this manuscript.

\section{References}

Adams, B., 2009. The Bükk mountain Szeletian: Old and new views on "transitional" material from the eponymous site of the Szeletian, in: Camps, M., Chauhan, P. (Eds.), Sourcebook of Paleolithic Transitions. Springer, New York, pp. 427-440. https://doi.org/10.1007/978-0-387-76487-0_28

Adams, D.C., 2016. Evaluating modularity in morphometric data: Challenges with the RV coefficient and a new test measure. Methods Ecol. Evol. 7, 565-572. https://doi.org/10.1111/2041-210X.12511

Adams, D.C., Coyller, M., Sherratt, E., 2016. geomorph: Geometric morphometric analysis of 2D/3D landmark data.

Adams, D.C., Otárola-Castillo, E., 2013. geomorph: An R package for the collection and analysis of geometric morphometric shape data. Methods Ecol. Evol. 4, 393-399. https://doi.org/10.1111/2041-210X.12035 
Ahler, S.A., Geib, P.R., 2000. Why flute? Folsom point design and adaptation. J. Archaeol. Sci. 27, 799-820. https://doi.org/10.1006/jasc. 1999.0503

Albrecht, G., 1977. Testing of materials as used for bone points of the Upper Palaeolithic, in: Camps-Faber, H. (Ed.), Méthodologie appliquée à l'industrie de l'os préhistorique. CNRS Éditions, Paris, pp. 119-126.

Albrecht, G., Hahn, J., Torke, W.G., 1972. Merkmalsanalyse von Geschoßspitzen des mittleren Jungpleistozäns in Mittel- und Osteuropa. Verlag W. Kohlhammer, Stuttgart.

Archer, W., Braun, D.R., 2010. Variability in bifacial technology at Elandsfontein, Western cape, South Africa: A geometric morphometric approach. J. Archaeol. Sci. 37, 201-209. https://doi.org/10.1016/j.jas.2009.09.033

Archer, W., Pop, C.M., Gunz, P., McPherron, S.P., 2016. What is Still Bay? Human biogeography and bifacial point variability. J. Hum. Evol. 97, 58-72. https://doi.org/10.1016/j.jhevol.2016.05.007

Binford, L.R., 1963. "Red ocher" caches from the Michigan area: A possible case of cultural drift. Southwest. J. Anthropol. 19, 89-108. https://doi.org/10.1086/soutjanth.19.1.3628924

Bon, F., 2002. L'Aurignacien entre mer et océan - Réflexion sur l'unité des phases anciennes de l'Aurignacien dans le sud de la France. Société préhistorique française, Paris.

Bookstein, F.L., 1989. Principal warps: Thin-plate splines and the decomposition of deformations. IEEE Trans. Pattern Anal. Mach. Intell. 11, 567-585. https://doi.org/10.1109/34.24792

Bookstein, F.L., 1991. Morphometric Tools for Landmark Data: Geometry and Biology. Cambridge University Press, New York.

Bookstein, F.L., 1996. Combining the tools of geometric morphometrics, in: Marcus, L.F., Corti, M., Loy, A., Naylor, G.J.P., Slice, D.E. (Eds.), Advances in Morphometrics. Springer, Boston, pp. 131-151. https://doi.org/10.1007/978-14757-9083-2_12

Bookstein, F.L., 1997. Landmark methods for forms without landmarks: Morphometrics of group differences in outline shape. Med. Image Anal. 1, 225-243. https://doi.org/10.1016/S1361-8415(97)85012-8

Bradfield, J., 2013. Investigating the potential of micro-focus computed tomography in the study of ancient bone tool function: results from actualistic experiments. J. Archaeol. Sci. 40, 2606-2613. https://doi.org/10.1016/j.jas.2013.02.007

Bradfield, J., Brand, T., 2013. Results of utilitarian and accidental breakage experiments on bone points. Archaeol. Anthropol. Sci. 1-12. https://doi.org/10.1007/s12520013-0136-5

Buchanan, B., Collard, M., 2010a. An assessment of the impact of resharpening on Paleoindian projectile point blade shape using geometric morphometric techniques, in: Lycett, S., Chauhan, P. (Eds.), New Perspectives on Old Stones. Springer, New York, pp. 255-273. https://doi.org/10.1007/978-1-44196861-6_11

Buchanan, B., Collard, M., 2010b. A geometric morphometrics-based assessment of blade shape differences amongst Paleoindian projectile point types from 
western North America. J. Archaeol. Sci. 37, 350-359.

https://doi.org/10.1016/j.jas.2009.09.047

Buchanan, B., O’Brien, M.J., Collard, M., 2013. Continent-wide or region-specific? A geometric morphometrics-based assessment of variation in Clovis point shape. Archaeol. Anthropol. Sci. 6, 145-162. https://doi.org/10.1007/s12520-013-0168-x

Cardillo, M., 2010. Some applications of geometric morphometrics to archaeology, in: Elewa, A.M.T. (Ed.), Morphometrics for Nonmorphometricians. Springer, Berlin, pp. 325-341. https://doi.org/10.1007/978-3-540-95853-6_15

Caux, S., 2015. Du territoire d'approvisionnement au territoire culturel. Pétroarchéologie et techno-économie du silex Grain de mil durant l'Aurignacien dans le Sud-Ouest de la France. PhD Thesis, Université de Bordeaux, Bordeaux.

Caux, S., 2017. Étude typo-technologique et pétro-archéologique des grattoirs Caminade. Première synthèse d'un outil caractéristique de l'Aurignacien récent du Sud-Ouest de la France. Bull. Soc. Prehist. Francaise 114, 237-256.

Charlin, J., González-José, R., 2012. Size and shape variation in Late Holocene projectile points of southern Patagonia: A geometric morphometric study. Am. Antiq. 77, 221-242. https://doi.org/10.7183/0002-7316.77.2.221

Christensen, M., 2004. II. Fiche caractères morphologiques, histologiques et mécaniques des matières dures d'origine animale, in: Ramseyer, D. (Ed.), Fiches de la Commission de nomenclature sur l'industrie de l'os préhistorique; Cahier XI: Matières et Techniques. Société préhistorique française, Paris, pp. 17-28.

Churchill, S.E., 1993. Weapon technology, prey size selection, and hunting methods in modern hunter-gatherers: Implications for hunting in the Palaeolithic and Mesolithic. Archeol. Pap. Am. Anthropol. Assoc. 4, 11-24. https://doi.org/10.1525/ap3a.1993.4.1.11

Clément, G., Leroy-Prost, C., 1977. Essai de classification automatique sur un algorithme de reconnaissance de formes d'une série de pointes à base fendue, in: CampsFabrer, H. (Ed.), Méthodologie appliquée à l'industrie de l'os préhistorique. CNRS Éditions, Paris, pp. 128-141.

Costa, A.G., 2010. A geometric morphometric assessment of plan shape in bone and stone Acheulean bifaces from the Middle Pleistocene site of Castel di Guido, Latium, Italy, in: Lycett, S., Chauhan, P. (Eds.), New Perspectives on Old Stones. Springer, New York, NY, pp. 23-41. https://doi.org/10.1007/978-14419-6861-6_2

Currey, J.D., 1979. Mechanical properties of bone tissues with greatly differing functions. J. Biomech. 12, 313-319. https://doi.org/10.1016/0021-9290(79)900733

Currey, J.D., 1984. Effects of differences in mineralization on the mechanical properties of bone. Philos. Trans. R. Soc. B 304, 509-518. https://doi.org/10.1098/rstb.1984.0042

Currey, J.D., 1999. The design of mineralised hard tissues for their mechanical functions. J. Exp. Biol. 202, 3285-3294.

Currey, J.D., 2002. Bones: Structure and Mechanics. Princeton University Press, Princeton, NJ. 
de Azevedo, S., Charlin, J., González-José, R., 2014. Identifying design and reduction effects on lithic projectile point shapes. J. Archaeol. Sci. 41, 297-307. https://doi.org/10.1016/j.jas.2013.08.013

Doyon, L., 2017a. La place de la grotte de l'Observatoire dans le paysage sociotechnologique aurignacien de l'Europe méridionale / The Grotte de l'Observatoire and its place in the Aurignacian socio-technological landscape of Southern Europe. Bull. Mus. Anthropol. préhist. Monaco 57, 21-33.

Doyon, L., 2017b. La variabilité technologique et morphométrique des pointes de projectile aurignacienne en matière osseuse : Implications cognitives, sociales et environnementales. PhD Thesis, Université de Montréal and Université de Bordeaux, Montreal and Bordeaux.

Doyon, L., under review. The cultural trajectories of Aurignacian osseous projectile points in Southern Europe. Quat. Int.

Doyon, L., Katz Knecht, H., 2014. The effects of use and resharpening on morphometric variability of Aurignacian antler projectile points. Mitteilungen der Ges. Für Urgesch. 23, 83-101.

Eerkens, J.W., 2000. Practice makes within 5\% of perfect: Visual perception, motor skill, and memory in artifact variation. Curr. Anthropol. 41, 663-668. https://doi.org/10.1086/317394

Eerkens, J.W., Lipo, C.P., 2005. Cultural transmission, copying errors, and the generation of variation in material culture and the archaeological record. J. Anthropol. Archaeol. 24, 316-334. https://doi.org/10.1016/j.jaa.2005.08.001

Ellis, C.J., 1997. Factors influencing the use of stone projectile tips - An ethnographic perspective, in: Knecht, H. (Ed.), Projectile Technology. Plenum Press, New York, pp. 37-74.

Féblot-Augustins, J., 1997. La circulation des matières premières au Paléolithique. ERAUL, Liège.

Féblot-Augustins, J., 1999. La mobilité des groupes paléolithiques. Bull. Mém. Société Anthropol. Paris 11, 219-260. https://doi.org/10.3406/bmsap.1999.2551

Féblot-Augustins, J., 2009. Revisiting European Upper Paleolithic raw material transfers: The demise of the cultural ecological paradigm?, in: Adams, B., Blades, B.S. (Eds.), Lithic Materials and Paleolithic Societies. Wiley-Blackwell, Oxford, pp. 25-46. https://doi.org/10.1002/9781444311976.ch3

Gandon, E., Roux, V., Coyle, T., 2014. Copying errors of potters from three cultures: Predictable directions for a so-called random phenomenon. J. Anthropol. Archaeol. 33, 99-107. https://doi.org/10.1016/j.jaa.2013.12.003

González-José, R., Charlin, J., 2012. Relative importance of modularity and other morphological attributes on different types of lithic point weapons: Assessing functional variations. PLOS ONE 7, e48009. https://doi.org/10.1371/journal.pone.0048009

Goutas, N., Tejero, J.-M., 2016. Osseous technology as a reflection of chronological, economic and sociological aspects of Palaeolithic hunter-gatherers: Examples from key Aurignacian and Gravettian sites in South-West Europe. Quat. Int. 403, 79-89. https://doi.org/10.1016/j.quaint.2015.11.143

Grimaldi, S., Porraz, G., Santaniello, F., 2014. Raw material procurement and land use in the northern Mediterranean Arc: Insight from the first Proto-Aurignacian of 
Riparo Mochi (Balzi Rossi, Italy). Quartär 61, 113-127. https://doi.org/10.7485/QU61_06

Hahn, J., 1988a. 1. Fiche Sagaie à base simple de tradition aurignacienne, in: Delporte, H., Mons, L. (Eds.), Fiches typologiques de l'industrie osseuse préhistorique; Cahier I. Sagaies. Publications de l'Université de Provence, Aix-en-Provence, pp. $1-17$.

Hahn, J., 1988b. 2. Fiche Sagaie à base fendue, in: Delporte, H., Mons, L. (Eds.), Fiches typologiques de l'industrie osseuse préhistorique; Cahier I. Sagaies. Publications de l'Université de Provence, Aix-en-Provence, pp. 1-21.

Haines, A.J., Crampton, J.S., 2000. Improvements to the method of Fourier shape analysis as applied in morphometric studies. Palaeontology 43, 765-783. https://doi.org/10.1111/1475-4983.00148

Hamilton, M.J., Buchanan, B., 2009. The accumulation of stochastic copying errors causes drift in culturally transmitted technologies: Quantifying Clovis evolutionary dynamics. J. Anthropol. Archaeol. 28, 55-69. https://doi.org/10.1016/j.jaa.2008.10.005

Heckel, C.E., 2018. Reconsidering production organization in the Early Upper Palaeolithic: The case for specialized production of Aurignacian beads. Quat. Int. 491, 11-20. https://doi.org/10.1016/j.quaint.2017.02.002

Henshilwood, C.S., Marean, C.W., 2003. The origin of modern human behavior: Critique of the models and their test implications. Curr. Anthropol. 44, 627-651. https://doi.org/10.1086/377665

Husson, F., Lê, S., Pagès, J., 2011. Exploratory Multivariate Analysis by Example Using R. Chapman \& Hall/CRC Press, Boca Raton.

Ingold, T., 2002. The Perception of the Environment: Essays on Livelihood, Dwelling and Skill, Routledge, London.

Klingenberg, C.P., 2008. Morphological integration and developmental modularity. Annu. Rev. Ecol. Evol. Syst. 39, 115-132. https://doi.org/10.1146/annurev.ecolsys.37.091305.110054

Klingenberg, C.P., 2009. Morphometric integration and modularity in configurations of landmarks: Tools for evaluating a priori hypotheses. Evol. Dev. 11, 405-421. https://doi.org/10.1111/j.1525-142X.2009.00347.x

Klingenberg, C.P., Marugán-Lobón, J., 2013. Evolutionary covariation in geometric morphometric data: Analyzing integration, modularity, and allometry in a phylogenetic context. Syst. Biol. 62, 591-610. https://doi.org/10.1093/sysbio/syt025

Knecht, H., 1989. Design variability in Aurignacian bone and antler projectile technologies: Split base points. Paper presented at the 54th Annual Meeting of the SAA: Culture Change and Variability in the Upper Paleolithic.

Knecht, H., 1991. Technological innovation and design during the Early Upper Paleolithic: A study of organic projectile technologies. PhD Thesis, New York University, New York.

Knecht, H., 1993. Early Upper Paleolithic approaches to bone and antler projectile technology. Archeol. Pap. Am. Anthropol. Assoc. 4 33-47. https://doi.org/10.1525/ap3a.1993.4.1.33 
834 Knecht, H., 1997. Projectile points of bone, antler, and stone - Experimental explorations 835 of manufacture and use, in: Knecht, H. (Ed.), Projectile Technology. Plenum

Koerper, H.C., Stickel, E.G., 1980. Cultural drift: A primary process of culture change. J. Anthropol. Res. 36, 463-469. https://doi.org/10.1086/jar.36.4.3629615

Le Brun-Ricalens, F., Bordes, J.-G., 2007. Les débuts de 1'Aurignacien en Europe occidentale : unité ou diversité ? Du territoire de subsistance au territoire culturel, in: Floss, H., Rouquerol, N. (Eds.), Les chemins de 1'art Aurignacien en Europe / Das Aurignacien und die Anfänge der Kunst in Europa. Actes du Colloque international d'Aurignac, 16-18 Sept. 2005. Musée-forum Aurignac, Toulouse, pp. 37-62.

Lê, S., Josse, J., Husson, F., 2008. FactoMineR: An R package for multivariate analysis. J. Stat. Softw. 25, 1-18.

Lemonnier, P., 1976. La description des chaînes opératoires: Contribution à l'analyse des systèmes techniques. Tech. Cult. 1, 100-151.

Liolios, D., 1999. Variabilité et caractéristiques du travail des matières osseuses au début de l'Aurignacien: approche technologique et économique. PhD Thesis, Paris XNanterre, Paris.

Lombard, M., Högberg, A., 2018. The Still Bay points of Apollo 11 rock shelter, Namibia: An inter-regional perspective. Azania Archaeol. Res. Afr. 53, 312340. https://doi.org/10.1080/0067270X.2018.1513240

Lycett, S.J., von Cramon-Taubadel, N., 2013. A 3D morphometric analysis of surface geometry in Levallois cores: Patterns of stability and variability across regions and their implications. J. Archaeol. Sci. 40, 1508-1517. https://doi.org/10.1016/j.jas.2012.11.005

Lycett, S.J., von Cramon-Taubadel, N., 2015. Toward a "quantitative genetic" approach to lithic variation. J. Archaeol. Method Theory 22, 646-675. https://doi.org/10.1007/s10816-013-9200-9

Lycett, S.J., von Cramon-Taubadel, N., Foley, R.A., 2006. A crossbeam co-ordinate caliper for the morphometric analysis of lithic nuclei: A description, test and empirical examples of application. J. Archaeol. Sci. 33, 847-861. https://doi.org/10.1016/j.jas.2005.10.014

Lycett, S.J., von Cramon-Taubadel, N., Gowlett, J.A.J., 2010. A comparative 3D geometric morphometric analysis of Victoria West cores: Implications for the origins of Levallois technology. J. Archaeol. Sci. 37, 1110-1117. https://doi.org/10.1016/j.jas.2009.12.011

Mackay, A., Stewart, B.A., Chase, B.M., 2014. Coalescence and fragmentation in the Late Pleistocene archaeology of southernmost Africa. J. Hum. Evol. 72, 26-51. https://doi.org/10.1016/j.jhevol.2014.03.003

MacLeod, N., 2018. The quantitative assessment of archaeological artifact groups: Beyond geometric morphometrics. Quat. Sci. Rev. 201, 319-348. https://doi.org/10.1016/j.quascirev.2018.08.024

Mardia, K.V., Dryden, I.L., 1989. Shape distribution for landmark data. Adv. Appl. Probab. 21, 742-755. https://doi.org/10.2307/1427764 
McBrearty, S., Brooks, A.S., 2000. The revolution that wasn't: A new interpretation of the origin of modern human behavior. J. Hum. Evol. 39, 453-563. https://doi.org/10.1006/jhev.2000.0435

Michel, A., 2010. L'Aurignacien récent (post-ancien) dans le Sud-Ouest de la France : variabilité des productions lithiques. Révision taphonomique et technoéconomique des sites de Caminade-Est, abri Pataud, Roc-de-Combe, Le Flageolet I, La Ferrassie et Combemenue. PhD Thesis, Université de Bordeaux 1, Bordeaux.

Minar, C.J., 2001. Motor skills and the learning process: The conservation of cordage final twist direction in communities of practice. J. Anthropol. Res. 57, 381-405. https://doi.org/10.2307/3631352

Moyers, R.E., Bookstein, F.L., 1979. The inappropriateness of conventional cephalometrics. Am. J. Orthod. 75, 599-617. https://doi.org/10.1016/00029416(79)90093-9

Newcomer, M., 1974. Study and replication of bone tools from Ksar Akil (Lebanon). World Archaeol. 6, 138-153.

Nuzhnyi, D., 1998. The preliminary results of experiments with Aurignacian split-based points production, hafting and usage. Préhistoire Eur. 13, 117-132.

Odar, B., 2011. Archers at Potočka zijalka? Arheol. Vestn. 62, 443-456.

Otte, M., 2014. Cro Magnon: Aux origines de notre humanité. Éditions Perrin, Paris.

Perez, S.I., Bernal, V., Gonzalez, P.N., 2006. Differences between sliding semi-landmark methods in geometric morphometrics, with an application to human craniofacial and dental variation. J. Anat. 208, 769-784. https://doi.org/10.1111/j.14697580.2006.00576.x

Pétillon, J.-M., 2006. Des Magdaléniens en armes: Technologie des armatures de projectile en bois de cervidé du Magdalénien supérieur de la Grotte d'Isturitz (Pyrénées-Atlantiques), Éditions du Cedarc, Treignes, Belgique.

Petřík, J., Sosna, D., Prokeš, L., Štefanisko, D., Galeta, P., 2016. Shape matters: assessing regional variation of Bell Beaker projectile points in Central Europe using geometric morphometrics. Archaeol. Anthropol. Sci. 1-12. https://doi.org/10.1007/s12520-016-0423-z

Picin, A., Vaquero, M., Weniger, G.-C., Carbonell, E., 2014. Flake morphologies and patterns of core configuration at the Abric Romaní rock-shelter: A geometric morphometric approach. Quat. Int. 350, 84-93. https://doi.org/10.1016/j.quaint.2014.05.004

Porraz, G., Simon, P., Pasquini, A., 2010. Identité technique et comportements économiques des groupes proto-aurignaciens à la grotte de l'Observatoire (principauté de Monaco). Gall. Préhistoire 52, 33-59.

R Development Core Team, 2008. R: A language and environment for statistical computing. R Foundation for Statistical Computing, Vienna, Austria.

Riede, F., Pedersen, J.B., 2018. Late Glacial human dispersals in Northern Europe and disequilibrium dynamics. Hum. Ecol. 46, 621-632. https://doi.org/10.1007/s10745-017-9964-8

Riel-Salvatore, J., Negrino, F., 2009. Early Upper Paleolithic population dynamics and raw material procurement patterns in Italy, in: Camps, M., Szmidt, C. (Eds.), The 
Mediterranean from 50000 to 25000 BP. Turning Points and New Directions. Oxbow Books, Oxford, pp. 211-230.

Riel-Salvatore, J., Negrino, F., 2018. Proto-Aurignacian lithic technology, mobility, and human niche construction: A case study from Riparo Bombrini, Italy, in: Robinson, E., Sellet, F. (Eds.), Lithic Technological Organization and Paleoenvironmental Change. Springer, Cham, pp. 163-187. https://doi.org/10.1007/978-3-319-64407-3_8

Rigaud, S., d'Errico, F., Vanhaeren, M., 2015. Ornaments reveal resistance of North European cultures to the spread of farming. PLoS ONE 10, e0121166. https://doi.org/10.1371/journal.pone.0121166

Rigaud, S., Manen, C., Lagrán, I.G.-M. de, 2018. Symbols in motion: Flexible cultural boundaries and the fast spread of the Neolithic in the western Mediterranean. PLOS ONE 13, e0196488. https://doi.org/10.1371/journal.pone.0196488

Rohlf, F.J., Slice, D., 1990. Extensions of the Procrustes method for the optimal superimposition of landmarks. Syst. Biol. 39, 40-59. https://doi.org/10.2307/2992207

Schillinger, K., Mesoudi, A., Lycett, S., 2014. Copying error and the cultural evolution of "additive" vs. "reductive" material traditions: An experimental assessment. Am. Antiq. 79, 128-143. https://doi.org/10.7183/0002-7316.79.1.128

Schillinger, K., Mesoudi, A., Lycett, S.J., 2017. Differences in manufacturing traditions and assemblage-level patterns: The origins of cultural differences in archaeological data. J. Archaeol. Method Theory 24, 640-658. https://doi.org/10.1007/s10816-016-9280-4

Shott, M.J., Trail, B.W., 2010. Exploring new approaches to lithic analysis: Laser scanning and geometric morphometrics. Lithic Technol. 35, 195-220. https://doi.org/10.1080/01977261.2010.11721090

Simon, H.A., 1962. The architecture of complexity. Proc. Am. Philos. Soc. 106, 467-482.

Slice, D.E., 2001. Landmark coordinates aligned by Procrustes analysis do not lie in Kendall's shape space. Syst. Biol. 50, 141-149. https://doi.org/10.1080/10635150119110

Slice, D.E., 2005. Modern Morphometrics in Physical Anthropology, Developments in Primatology: Progress and Prospects. Kluwer Academic/Plenum Publisher, New York.

Smith, H.L., DeWitt, T.J., 2017. The northern fluted point complex: Technological and morphological evidence of adaptation and risk in the late Pleistocene-early Holocene Arctic. Archaeol. Anthropol. Sci. 9, 1799-1823. https://doi.org/10.1007/s12520-016-0335-y

Tartar, É., White, R., 2013. The manufacture of Aurignacian split-based points: An experimental challenge. J. Archaeol. Sci. 40, 2723-2745. https://doi.org/10.1016/j.jas.2013.02.009

Tejero, J.-M., 2014. Towards complexity in osseous raw material exploitation by the first anatomically modern humans in Europe: Aurignacian antler working. J. Anthropol. Archaeol. 36, 72-92. https://doi.org/10.1016/j.jaa.2014.08.004

Tejero, J.-M., 2016. Spanish Aurignacian projectile points: An example of the first European Paleolithic hunting weapons in osseous materials, in: Langley, M.C. (Ed.), Osseous Projectile Weaponry: Towards an Understanding of Pleistocene 
1006

1007

1008

1009

1010

Cultural Variability. Vertebrate Paleobiology and Paleoanthropology. Springer, Dordrecht, pp. 55-70. https://doi.org/10.1007/978-94-024-0899-7_5

Teyssandier, N., 2007. En route vers l'Ouest? Les débuts de l'Aurignacien en Europe centrale et dans les Balkans, in: Floss, H., Rouquerol, N. (Eds.), Les chemins de l'art Aurignacien en Europe / Das Aurignacien und die Anfänge der Kunst in Europa. Actes du Colloque international d'Aurignac, 16-18 Sept. 2005. Muséeforum Aurignac, Toulouse, pp. 117-130.

Thomas, K.A., Story, B.A., Eren, M.I., Buchanan, B., Andrews, B.N., O’Brien, M.J., Meltzer, D.J., 2017. Explaining the origin of fluting in North American Pleistocene weaponry. J. Archaeol. Sci. 81, 23-30. https://doi.org/10.1016/j.jas.2017.03.004

Thulman, D.K., 2012. Discriminating Paleoindian point types from Florida using landmark geometric morphometrics. J. Archaeol. Sci. 39, 1599-1607. https://doi.org/10.1016/j.jas.2012.01.004

Turk, I., 2002. Morfometrična analiza zgodnjih koščenih konic v povezavi z najdbami koščenih konic iz Divjih bab I. Arheol. Vestn. 53, 9-29.

Turk, I., 2003. Morphometric analysis of early bone points in connection with finds of bone points from Divje babe I. Curr. Archaeol. 187, 28-49.

Turk, I., 2005. Zagovor morfometrične analize koščenih konic. Arheol. Vestn. 56, 453464.

Vanhaeren, M., d'Errico, F., 2006. Aurignacian ethno-linguistic geography of Europe revealed by personal ornaments. J. Archaeol. Sci. 33, 1105-1128.

Velhagen, W.A., Roth, V.L., 1997. Scaling of the mandible in squirrels. J. Morphol. 232, 107-132. https://doi.org/10.1002/(SICI)1097-4687(199705)232:2<107::AIDJMOR1>3.0.CO;2-7

Vercoutère, C., Patou-Mathis, M., 2010. Chapitre VIII - L'animal comme ressource alimentaire... pas seulement, in: Otte, M. (Ed.), Les Aurignaciens. Éditions Errance, Paris, pp. 17-32.

Withalm, G., 2004. New evidence for cave bear hunting from Potočka zijalka (Slovenia), in: Pacher, M., Pohar, V., Rabeder, G. (Eds.), Potočka Zijalka. Palaeontological and Archaeological Results of the Campaigns 1997-2000, Mitteilungen der Kommission für Quartärforschung der österreichischen Akademie der Wissenschaften. Österreichischen Akademie der Wissenschaften, Vienna, pp. 219-235.

Zelditch, M.L., Lundrigan, B.L., Garland, T., 2004. Developmental regulation of skull morphology. I. Ontogenetic dynamics of variance. Evol. Dev. 6, 194-206. https://doi.org/10.1111/j.1525-142X.2004.04025.x 
1011 Figure 1: a: Polar grid superimposed on a split-based point from Cova de L'Arbreda (the green line linking landmarks 1 and 19 corresponds to the maximum width; the blue line linking landmarks 10 and 28 corresponds to the maximum length; the green crosses indicate where the landmarks were recorded; Scale $=1 \mathrm{~cm}$ ); b: Corresponding landmarks coordinates saved in the *.nts file; c: Generalized Procrustes Analysis (GPA) of the complete split-based points included in the present study; d: Demarcation between the distal and proximal modules and their corresponding landmarks.

Figure 2: a: Results of the modularity test for split-based points (observed $C R=0.885 ; p$ $=0.001$ ); b: Results of the modularity test for massive-based points (observed $C R=$ $0.92 ; p=0.038$ ). The black arrows indicate the observed $C R$ value for each sample considered.

Figure 3: a: Projection of the first two principal components of shape variation for the proximal portion of split- (red) and massive-based (black) points; b: Projection of the first two principal components of shape variation for the proximal portion of massive-based points made of antler (black), bone (red), and ivory (green). Note: Only the specimens with all the landmarks of the proximal module are included in these graphs.

Figure 4: a: Projection of the first two principal components of shape variation for the distal portion of split- (red) and massive-based (black) points; b: Projection of the first two principal components of shape variation for the distal portion of armatures made of antler (black), bone (red), and ivory (green). Note: Only the specimens with all the landmarks of the distal module are included in these graphs.

Figure 5: a: Projection of the hierarchical clustering tree for split-based points on the factor map; b: Projection of the first two principal components of shape variation for the proximal portion of split-based points by shape cluster; c: Range of variation of the proximal length by shape cluster. Note: The horizontal line indicates the average for the sample considered in the present study.

Figure 6: Principal warps for the shape variation of the proximal portion and sample of split-based points assigned to their corresponding shape cluster. Scales $=1 \mathrm{~cm}$. 
Note: Grey scaled photographs are part of the Heidi Katz Knecht Collection curated at the Hominin Dispersal Research Group Laboratory at the University of Montréal.

1043 Figure 7: a: Projection of the hierarchical clustering tree for massive-based points on the

1044 factor map; b: Projection of the first two principal components of shape variation for the proximal portion of massive-based points by shape cluster. Note: The dashlined box highlights the data for the shape M04; c: Range of variation of the proximal length by shape cluster. Notes: 1) The horizontal line indicates the average for the sample considered in the present study; 2) The dash-lined box highlights the data for the shape M04.

Figure 8: Principal warps for the shape variation of the proximal portion and sample of massive-based points assigned to their corresponding shape cluster. Scales $=1 \mathrm{~cm}$. Note: Grey scaled photographs are part of the Heidi Katz Knecht Collection curated at the Hominin Dispersal Research Group Laboratory at the University of Montréal.

Table 1: Contextual data of the sample of points considered in the present study.

Table 2: Percentage and location of damages recorded on the specimens analyzed in the present study.

Table 3: Over- (black) and underrepresentation (red) of split-based point proximal shape by region and by site.

Table 4: Over- (black) and underrepresentation (red) of massive-based point proximal shape by region and by site. 
a)

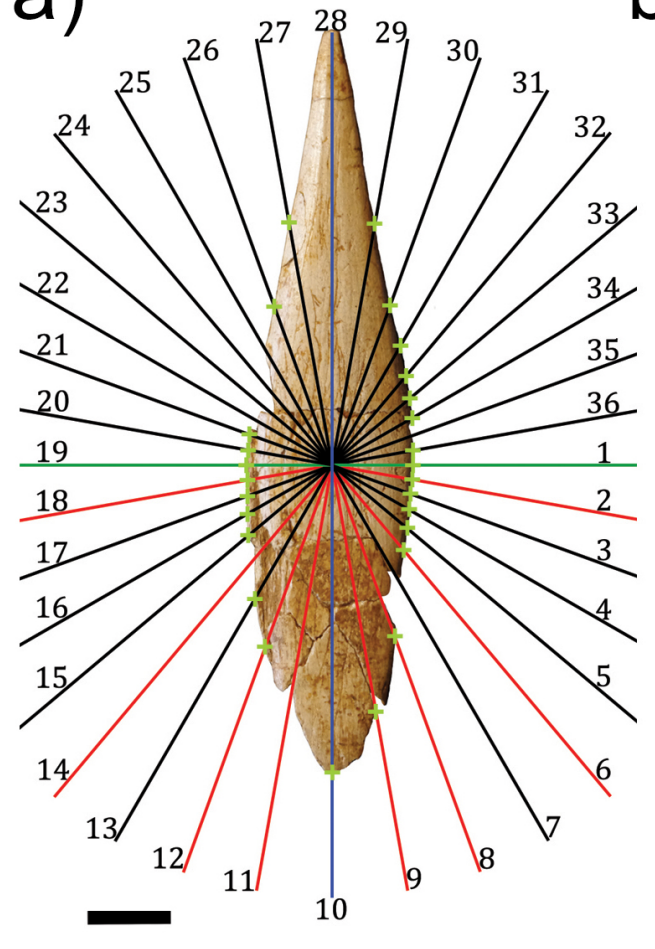

b)

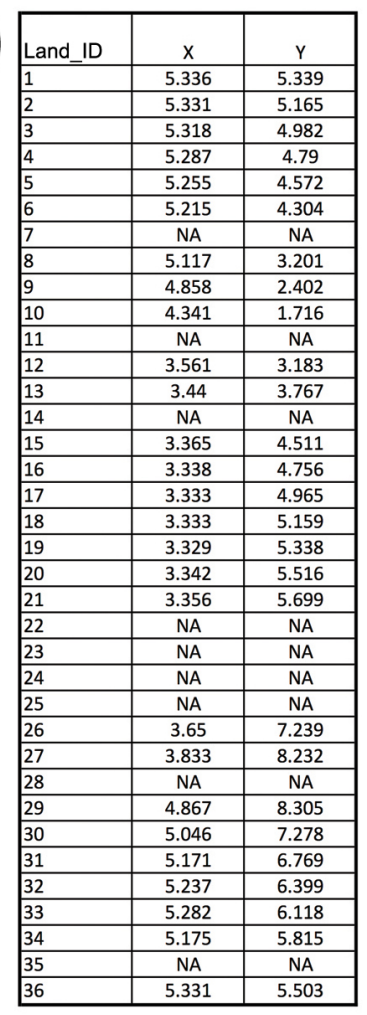

c)

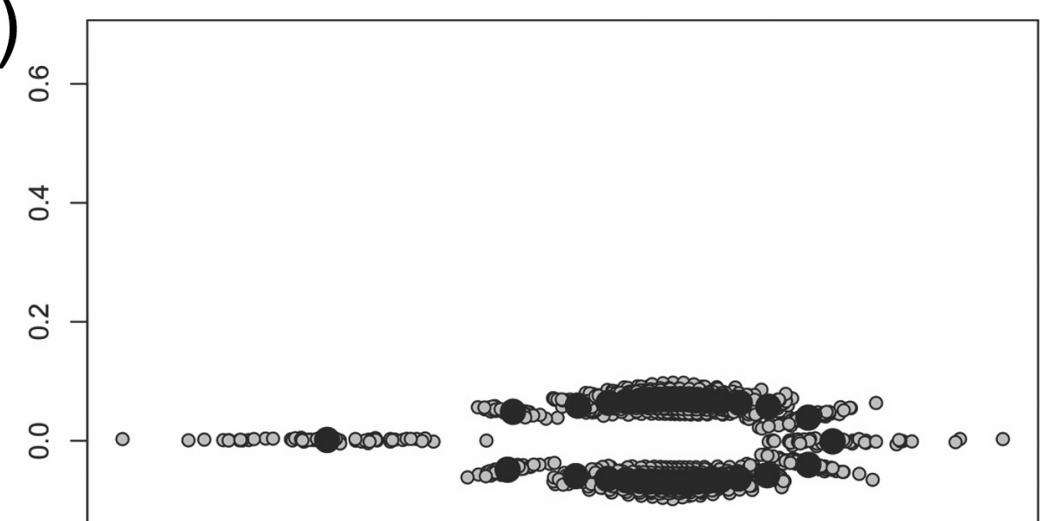

พฺ
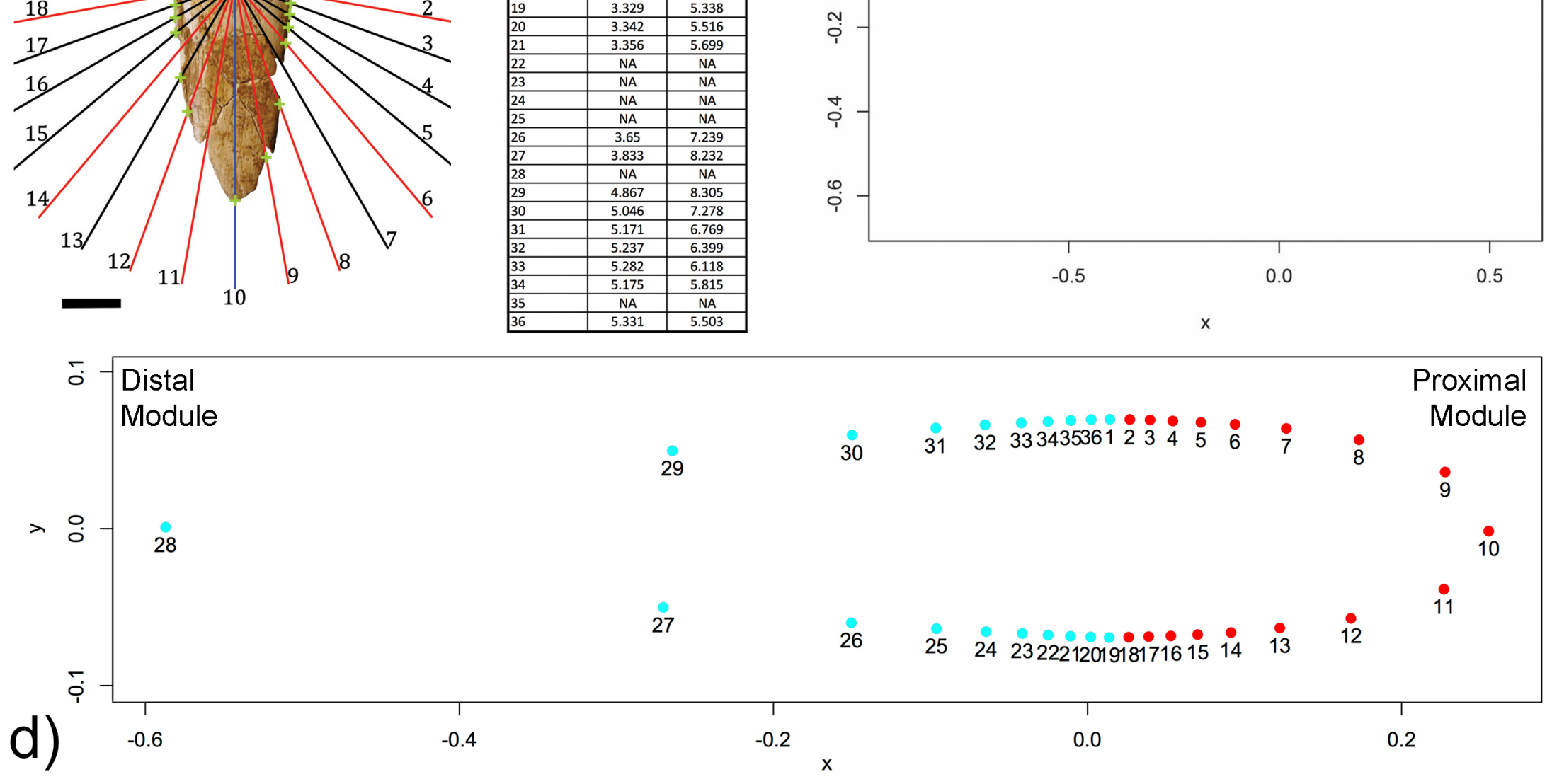
a)
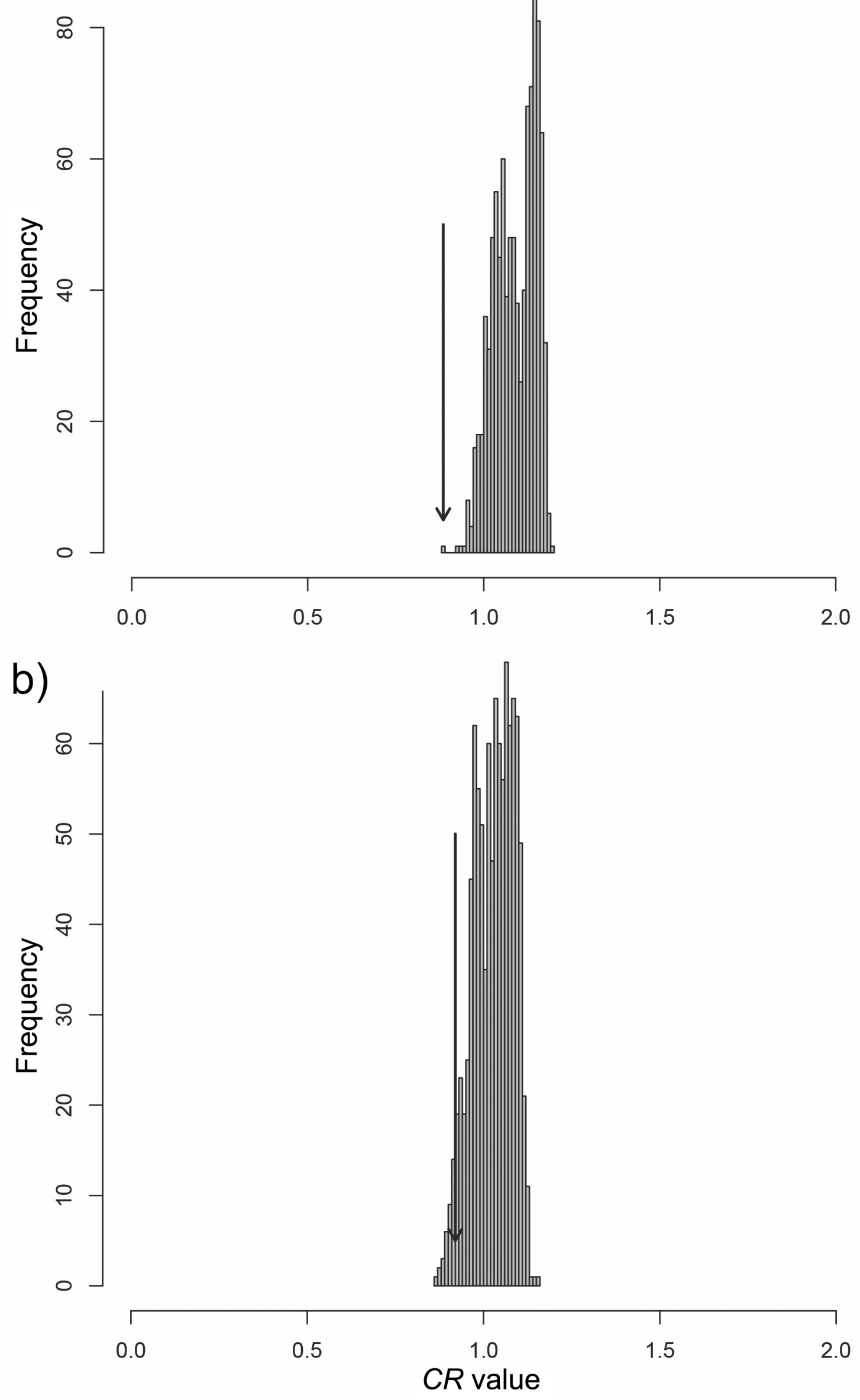

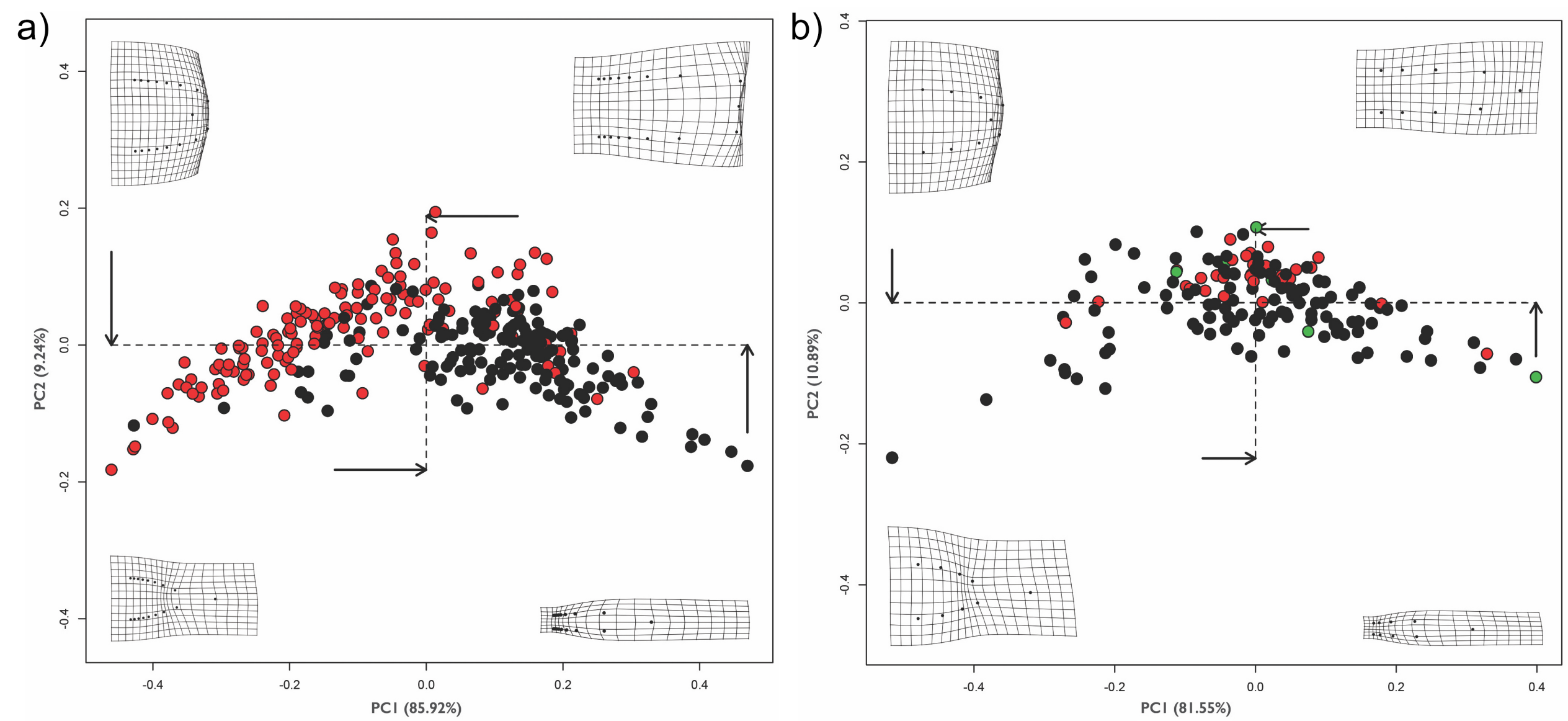

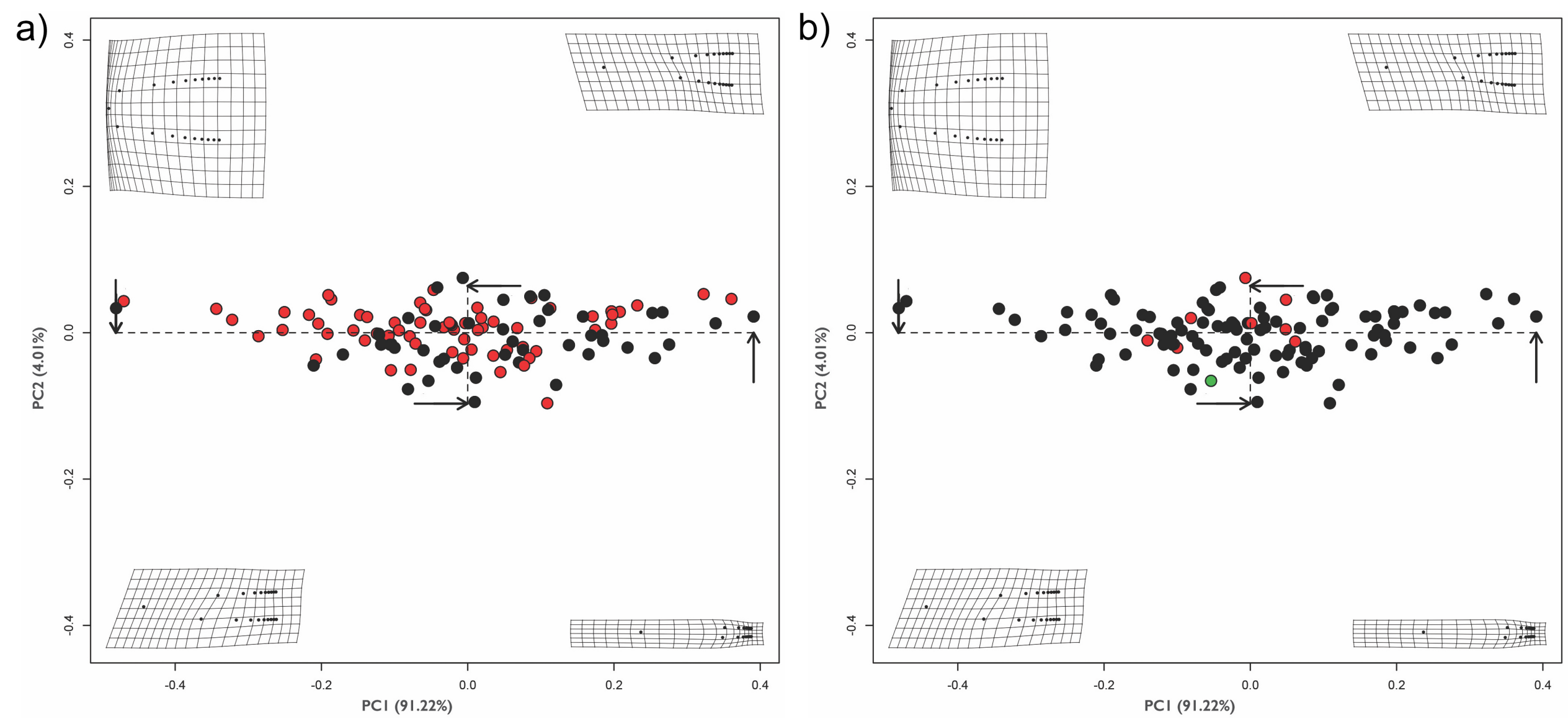
a)

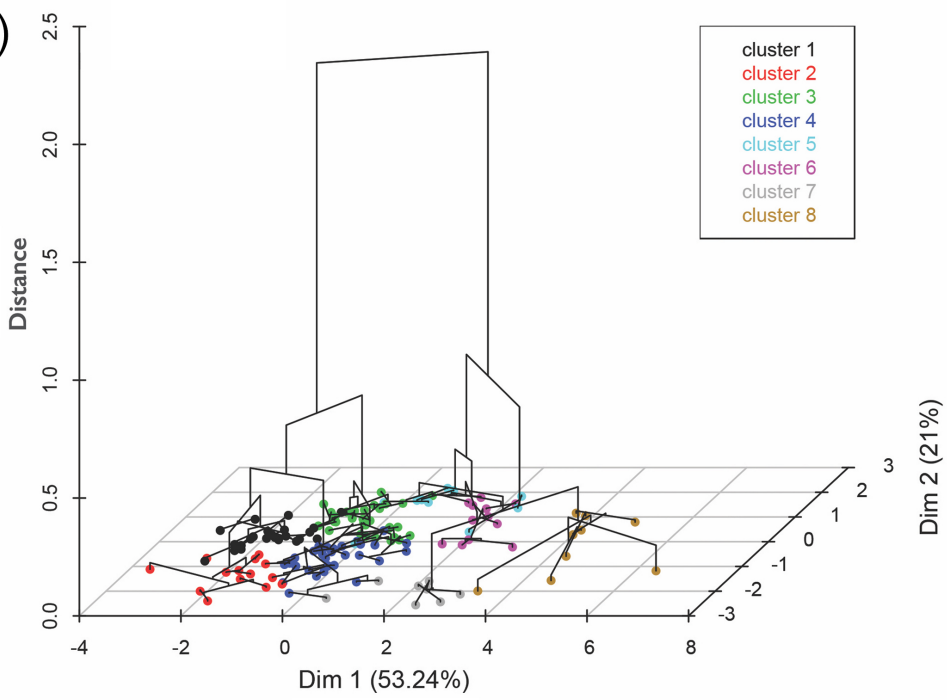

b)

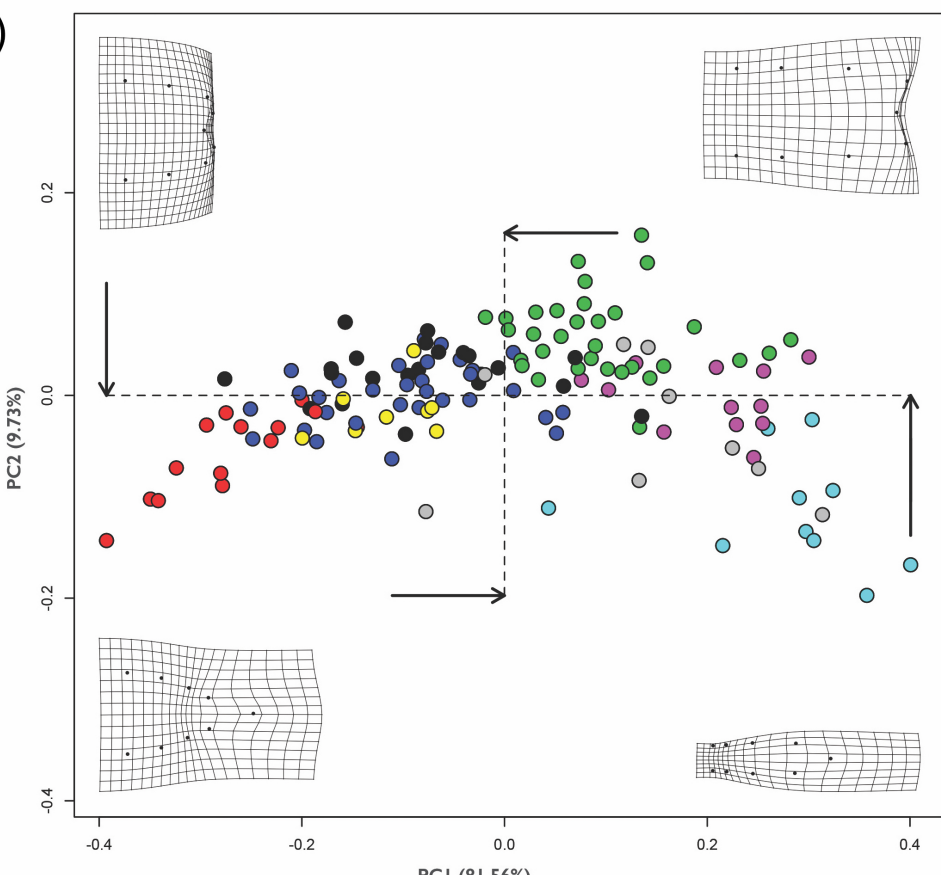

c)

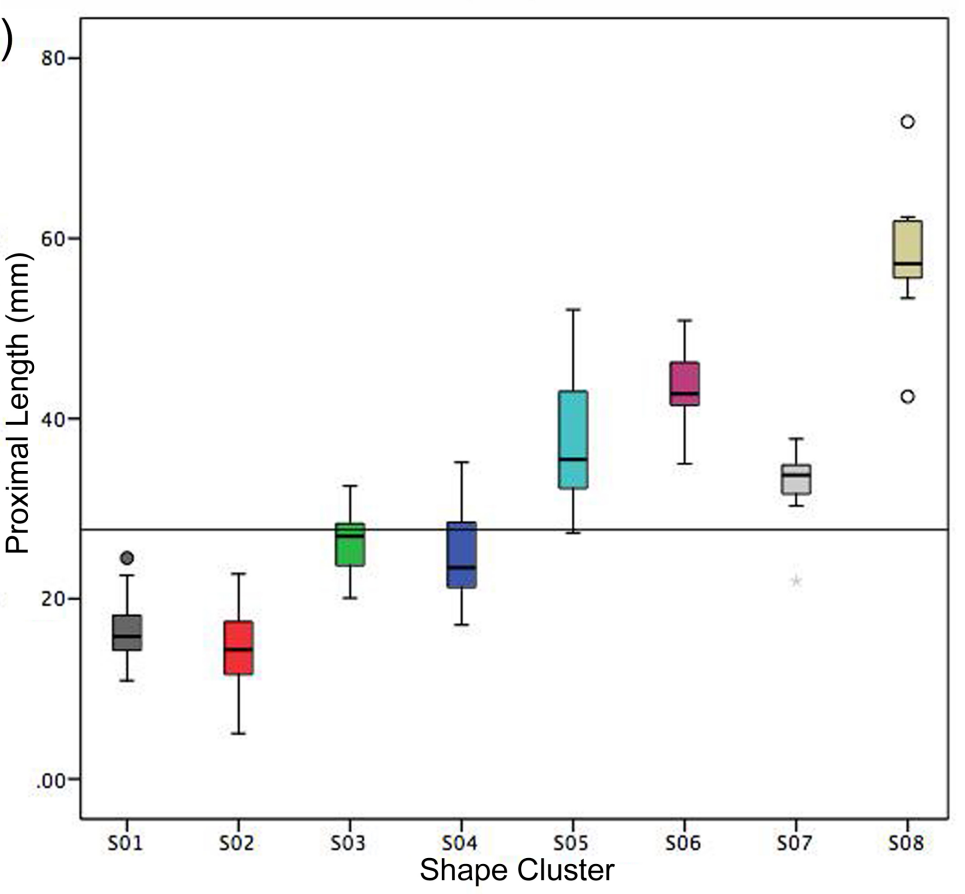



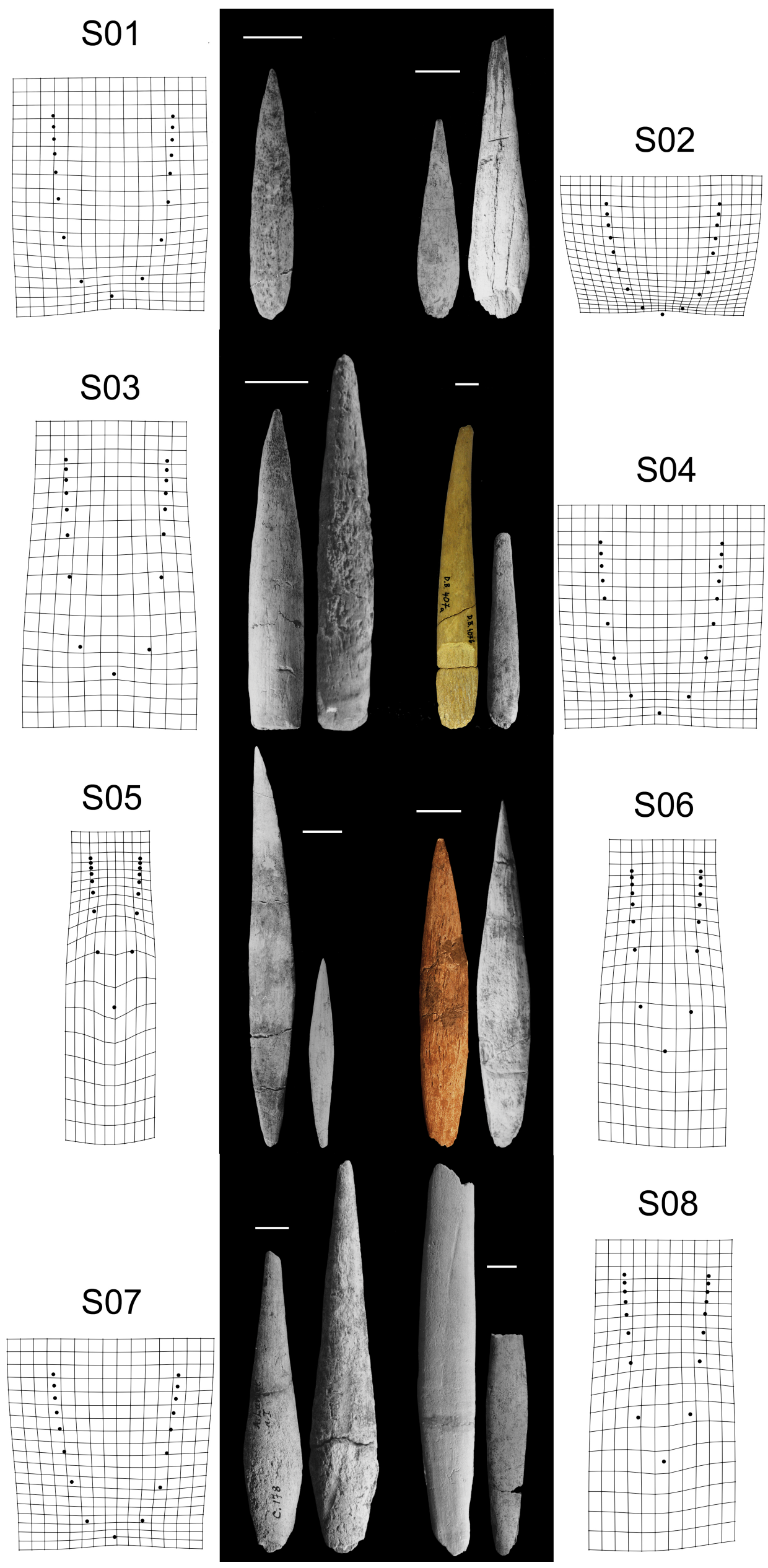

S08

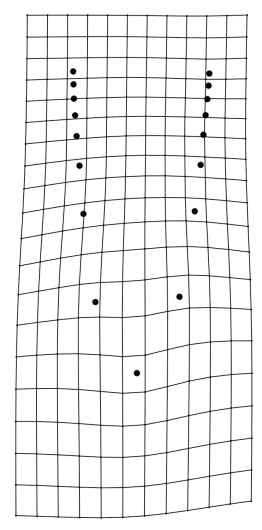


a)

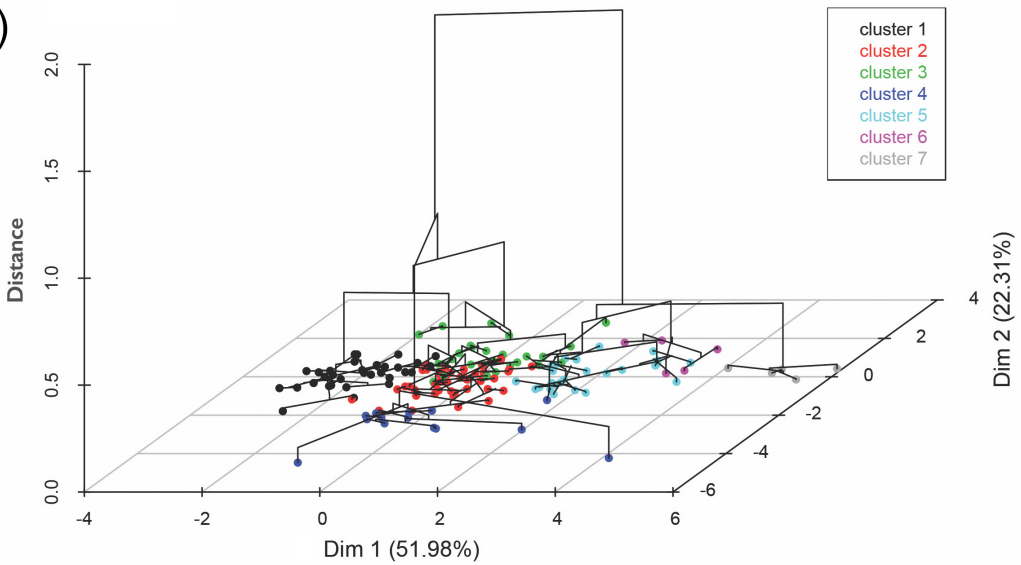

b)

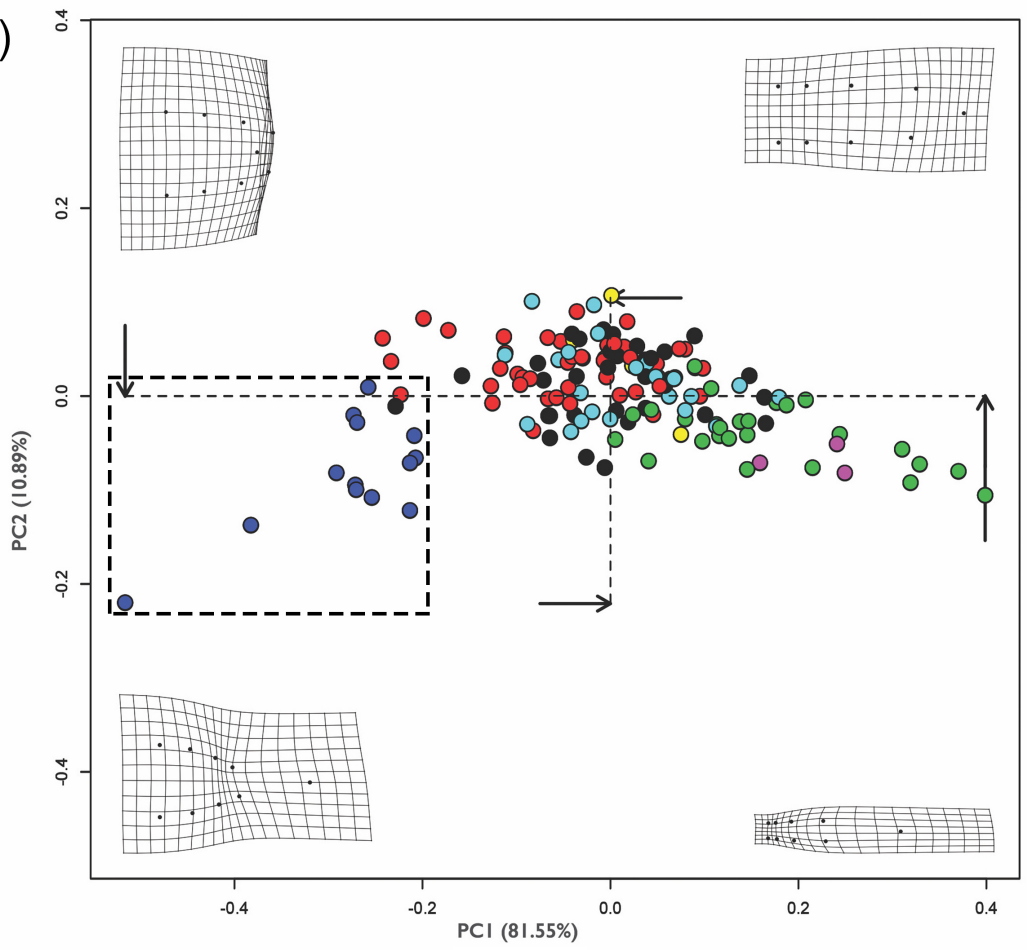

c)

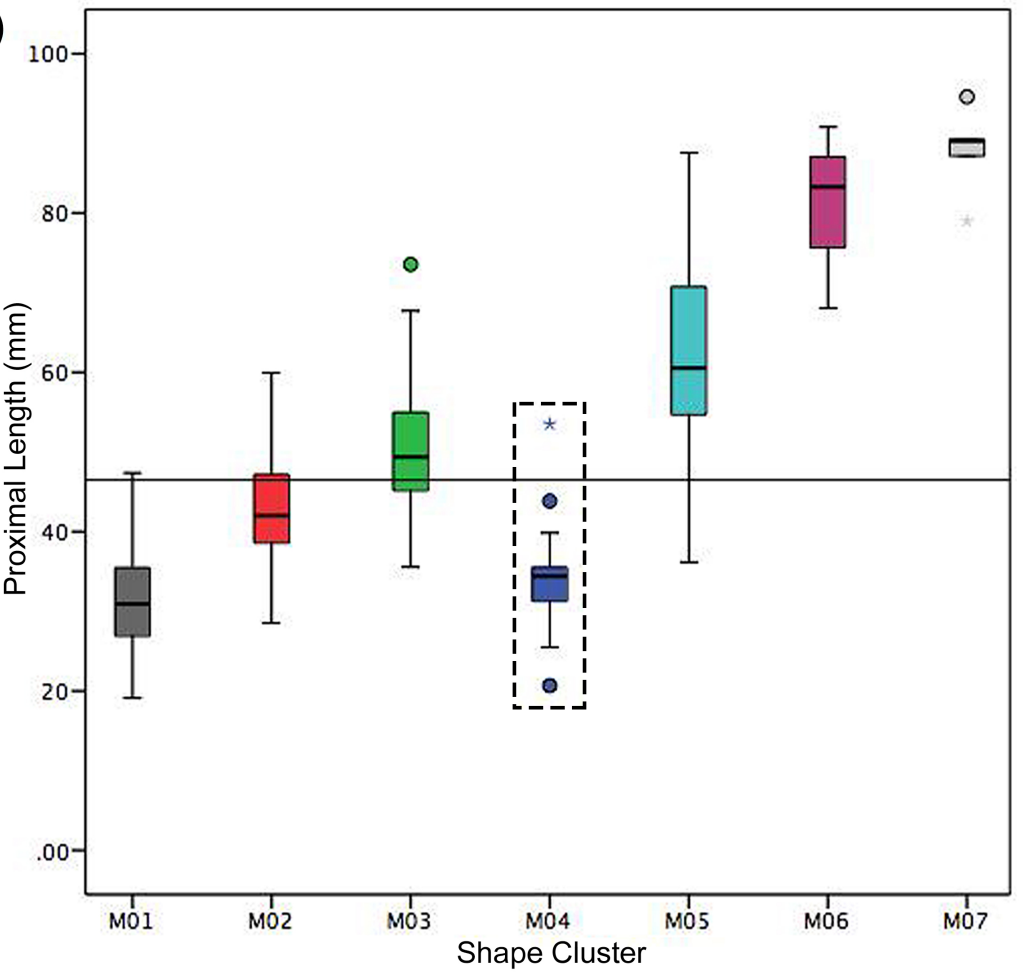




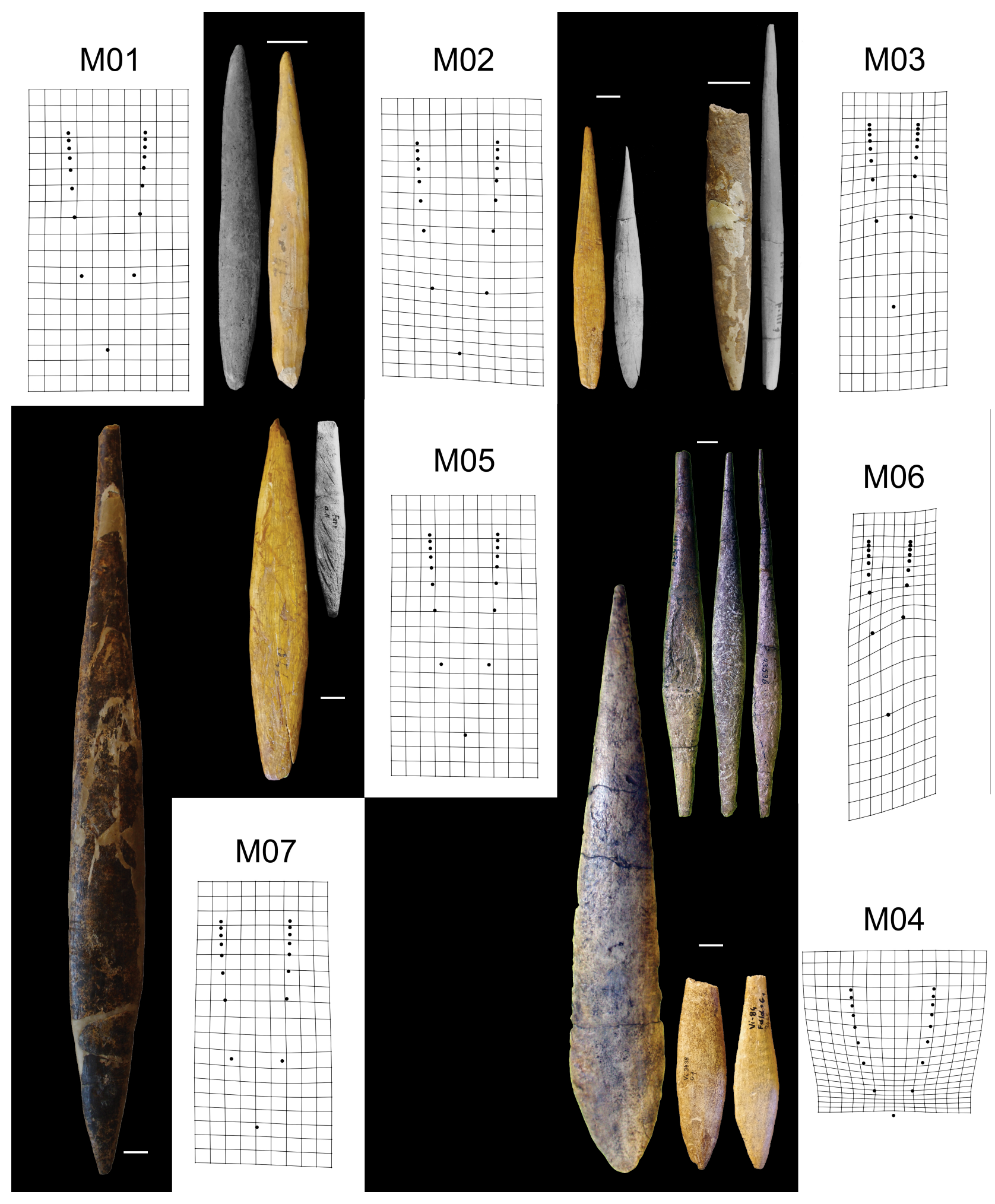

